\title{
Long-term efficacy and safety of patisiran in patients with
}

\section{hereditary transthyretin amyloidosis with polyneuropathy: Interim}

\section{1-year results from an open-label extension study}

David Adams, Michael Polydefkis, Alejandra González-Duarte, Jonas Wixner, Arnt V Kristen, Hartmut H Schmidt, John L Berk, Inés Asunción Losada López, Angela Dispenzieri, Dianna Quan, Isabel M Conceição, Michel S Slama, Julian D Gillmore, Theodoros Kyriakides, Senda Ajroud-Driss, Márcia Waddington-Cruz, Michelle M Mezei, Violaine Planté-Bordeneuve, Shahram Attarian, Elizabeth Mauricio, Thomas H Brannagan III, Mitsuharu Ueda, Emre Aldinc, Jing Jing Wang, Matthew T White, John Vest, Erhan Berber, Marianne T Sweetser, Teresa Coelho, on behalf of the patisiran Global OLE study group*

Neurology Department, APHP, CHU Bicêtre, INSERM U1195, Université Paris-Saclay, France (Prof David Adams MD), Department of Neurology, Johns Hopkins University School of Medicine, Baltimore, MD, USA (Prof Michael Polydefkis MD), Instituto Nacional de Ciencias Médicas y Nutrición Salvador Zubirán, México D.F., México (Alejandra González-Duarte MD), Department of Public Health and Clinical Medicine, Umeå University, Umeå, Sweden (Jonas Wixner PhD), University of Heidelberg, Heidelberg, Germany (Prof Arnt V Kristen MD), University of Münster, Münster, Germany (Prof Dr med. Hartmut H Schmidt MD), Boston Medical Center, Boston, MA, USA (Prof John L Berk MD), Balearic Islands Health Research Institute (IdSBa), Palma, Spain (Prof Inés Asunción Losada López MD), Division of Hematology, Mayo Clinic, Rochester, MN, USA (Prof Angela Dispenzieri MD), University of Colorado, Denver, CO, USA (Dianna Quan MD), CHULN, Hospital de Santa Maria and Faculdade de Medicina, Lisbon, Portugal (Isabel M Conceição MD), Cardiology Department, Centre de Compétence Amylose Cardiaque, CHU X. Bichat APHP, Université Paris Sud, Paris, France (Prof Michel S Slama MD), National Amyloidosis Centre, University College London, Royal Free Hospital, London, UK (Prof Julian D Gillmore PhD), Neurology 
Clinic A, The Cyprus Institute of Neurology and Genetics, Nicosia, Cyprus (Prof Theodoros Kyriakides MD), Department of Neurology, Northwestern University Feinberg School of Medicine, Chicago, IL, USA (Senda Ajroud-Driss MD), Hospital Universitario Clementino Fraga Filho-UFRJ, Rio de Janeiro, Brazil (Márcia Waddington-Cruz PhD), Division of Neurology, Department of Medicine, University of British Columbia, Vancouver, Canada (Michelle M Mezei MDCM), Neurology Amyloid network, CHU Henri Mondor - Assistance Publique Hopitaux de Paris, Creteil, France (Prof Violaine Planté-Bordeneuve PhD), Neuromuscular disorders and ALS Department, CHU La Timone, Marseille, France (Prof Shahram Attarian MD), Mayo Clinic, Jacksonville, FL, USA (Elizabeth Mauricio, MD), Columbia University, College of Physicians and Surgeons, Neurology Department, New York, NY, USA (Prof Thomas H Brannagan III MD), Kumamoto University Hospital, Department of Neurology, Kumamoto, Japan (Mitsuharu Ueda PhD), Alnylam Pharmaceuticals, Cambridge, MA, USA (Emre Aldinc MD, Matthew T White PhD, John Vest MD, Marianne T Sweetser MD), formerly of Alnylam Pharmaceuticals, Cambridge, MA, USA (Jing Jing Wang MD), Myokardia, Brisbane, CA, USA; formerly of Alnylam Pharmaceuticals, Cambridge, MA, USA (Erhan Berber MD), Hospital de Santo António, Centro Hospitalar do Porto, Porto, Portugal (Teresa Coelho PhD)

*Members listed in the appendix, pp 11-18

Correspondence to: Prof David Adams, APHP, National reference centre for FAP (NNERF), CHU Bicêtre, INSERM U1195, Université Paris Saclay, Neurology Department, 78 rue du Général Leclerc, 94270 Le Kremlin Bicêtre Cedex, France

Email: david.adams@aphp.fr

Telephone: $00331+145212711$ 


\section{Summary}

Background Hereditary transthyretin (ATTRv) amyloidosis is a rare, inherited, progressive disease caused by mutations in the transthyretin (TTR) gene. We aimed to assess the efficacy and safety of long-term treatment with patisiran, an RNA interference therapeutic that inhibits TTR production, in patients with ATTRv amyloidosis with polyneuropathy.

Methods This multi-country, multi-centre, open-label extension (OLE) trial enrolled patients at 43 sites in 19 countries as of 24 September 2018. Patients were eligible if they had completed the phase 3 APOLLO (randomised, double-blind, placebo-controlled [2:1], 18-month study) or phase 2 OLE (single-arm, 24-month study) parent studies and tolerated the study drug. Eligible patients from APOLLO (APOLLO-patisiran [received patisiran during APOLLO] and APOLLO-placebo [received placebo during APOLLO] groups) and the phase 2 OLE (phase 2 OLE patisiran group) studies enrolled in this Global OLE trial and receive patisiran $0.3 \mathrm{mg} / \mathrm{kg}$ by intravenous infusion every 3 weeks for up to 5 years. Efficacy assessments include measures of polyneuropathy (modified Neuropathy Impairment Score +7 [mNIS+7]), quality of life, autonomic symptoms, nutritional status, disability, ambulation status, motor function, and cardiac stress. Patients included in the current efficacy analyses are those who had completed 12-month efficacy assessments as of the data cut-off. Safety analyses included all patients who received $\geq 1$ dose of patisiran up to the data cut-off. The Global OLE is ongoing with no new enrolment, and current findings are based on the 12-month interim analysis. The study is registered with ClinicalTrials.gov, NCT02510261.

Findings Between 13 July 2015 and 21 August 2017, 211/212 patients were enrolled: 137, 49, and 25 patients from the APOLLO-patisiran, APOLLO-placebo, and phase 2 OLE patisiran groups, respectively. At the data cut-off on 24 September 2018, 126/137 (92\%), 38/49 (78\%), and 25/25 (100\%) patients in the APOLLO-patisiran, APOLLO-placebo, and phase 2 OLE patisiran groups, respectively, had completed 12-month assessments. At 12 months, improvements in mNIS+7 with 
patisiran in parent studies were sustained from parent study baseline with treatment in the Global OLE (mean change [95\% $\mathrm{Cl}],-4.0[-7 \cdot 7$ to -0.3$]$ APOLLO-patisiran; $-4.7[-11.9$ to $2 \cdot 4]$ phase 2 OLE patisiran). Mean mNIS+7 score improved from Global OLE enrolment in the APOLLO-placebo group (mean change from Global OLE enrolment [95\% Cl] -1.4 [-6.2 to 3.5]). Overall, 204/211 (97\%) patients reported adverse events (AEs), $82 / 211$ (39\%) reported serious AEs, and there were $23 / 211$ (11\%) deaths. Serious AEs were more frequent in the APOLLO-placebo group (28/49 [57\%]) than in the APOLLO-patisiran (48/137 [35\%]) or phase 2 OLE patisiran (6/25 [24\%]) groups. The most common treatment-related AE was mild or moderate infusion-related reactions. The frequency of deaths in the Global OLE was higher in the APOLLO-placebo group (13/49 [27\%]), who had greater disease burden at Global OLE enrolment, than the APOLLO-patisiran (10/137 [7\%]) and phase 2 OLE patisiran (0/25 [0\%]) groups.

Interpretation Patisiran demonstrates maintained efficacy with an acceptable safety profile in patients with ATTRv amyloidosis with polyneuropathy. Those receiving delayed treatment accumulated greater disease burden while untreated but benefited after initiating treatment, highlighting the need for early treatment to prevent deterioration. The continued long-term followup of patients in this Global OLE study will be important for the overall assessment of the efficacy and safety with patisiran.

Funding This study was funded by Alnylam Pharmaceuticals.

\section{Introduction}

Hereditary transthyretin-mediated (hATTR) amyloidosis, also known as ATTRv ( $v$ for variant) amyloidosis, is a rare, inherited, progressive disease caused by mutations in the transthyretin (TTR) gene that result in misfolded TTR accumulating as amyloid deposits in multiple organs and tissues, including somatic and autonomic nerves and the heart. ${ }^{1-3}$ The majority of patients develop a mixed 
phenotype of both polyneuropathy and cardiomyopathy, ${ }^{4-7}$ and experience rapid progression after clinical disease onset. ${ }^{1}$ The median survival for untreated patients is 4.7 years following diagnosis, with reduced survival (median 3.4 years) ${ }^{8}$ for patients presenting with cardiomyopathy. ${ }^{9}$ Risk factors for poor prognosis include advanced polyneuropathy, non-V30M ( $p$. V50M) genotype with late-onset disease ( $>50$ years), and cardiac involvement. ${ }^{8,9}$ Treatments such as orthotopic liver transplantation $(\mathrm{OLT})^{10}$ and TTR stabilisers (tafamidis, ${ }^{11}$ diflunisal ${ }^{12}$ ) may slow the natural progression of ATTRv amyloidosis in the early stages of the disease, yet worsening of neurological function and quality of life (QOL) are often observed ${ }^{11}$ (due to continuing deposition of wild-type [wt] TTR in the case of OLT). ${ }^{10}$

Patisiran is a lipid nanoparticle RNA interference (RNAi) therapeutic that reduces serum TTR levels by inhibiting hepatic synthesis of the disease-causing mutant and wt TTR proteins, ${ }^{13}$ thereby reducing the source of amyloid fibrils. The phase 3 placebo-controlled APOLLO study and the phase 2 open-label extension (OLE) study demonstrated that patisiran achieved robust, rapid, and sustained reduction of serum TTR levels from baseline in patients with ATTRv amyloidosis with polyneuropathy. ${ }^{6,14}$ In the 18 -month APOLLO study, patients treated with patisiran $0 \cdot 3$ milligrams/kilogram (mg/kg) intravenous (IV) infusion every 3 weeks ( $q 3 \mathrm{w}$ ) compared with placebo improved in autonomic, sensory, and motor neuropathy as measured by the primary endpoint modified Neuropathy Impairment Score $+7(\mathrm{mNIS}+7)$ as well as across all secondary endpoints including QOL, motor strength, disability, gait speed, nutritional status, ${ }^{6,15}$ and exploratory cardiac structure/function endpoints in the pre-specified cardiac sub-population. ${ }^{16}$ Patisiran also improved endpoints related to polyneuropathy and QOL, such as mNIS+7 and Norfolk QOL-Diabetic Neuropathy questionnaire (Norfolk QOL-DN), at 18 months compared with baseline in the majority ( $56 \%$ and $51 \%$, respectively) of patients, suggesting reversal of the polyneuropathy of the disease. ${ }^{6}$ In APOLLO, the majority of adverse events (AEs) observed were mild or moderate in intensity and the frequency of severe AEs and serious adverse events (SAEs) were similar between the patisiran and placebo groups. ${ }^{6}$ The primary objective of the 24-month phase 2 OLE was to evaluate the safety 
and tolerability of patisiran, and the study demonstrated both safety and secondary efficacy results consistent with those reported in APOLLO. ${ }^{14}$ Eligible patients who completed APOLLO (patisiran or placebo arm) or the phase 2 OLE were able to enrol into the Global OLE which aims to assess the long-term efficacy and safety of patisiran in patients with ATTRv amyloidosis with polyneuropathy. Here, interim efficacy and safety data from the ongoing Global OLE are discussed.

\section{Methods}

\section{Study design and participants}

The Global OLE (NCT02510261) is a multi-country, multi-centre, ongoing OLE trial which enrolled patients at 43 sites in 19 countries as of 24 September 2018 (appendix, p 3). Eligible patients included patients who completed the APOLLO or phase 2 OLE studies, ${ }^{6,14}$ and, in the opinion of the investigator, tolerated the study drug.

This study is being conducted according to the guidelines of the International Conference on Harmonization, the World Health Organization Declaration of Helsinki, and the Health Insurance Portability and Accountability Act of 1996. Written informed consent was obtained from all patients before undergoing any protocol-specific tests or procedures that are not part of routine care. The study protocol (appendix, p 2) and all amendments were approved by the local Institutional Review Boards and Ethics Committees.

\section{Randomisation and masking}

Due to the nature of an OLE study, there was no randomisation or masking in the Global OLE study. However, the patients in the Global OLE came from one of the following three groups: APOLLOplacebo (received placebo in APOLLO; started patisiran in the Global OLE); APOLLO-patisiran (received patisiran in APOLLO; continued patisiran in the Global OLE); and phase 2 OLE patisiran (received patisiran in the phase 2 OLE; continued patisiran in the Global OLE). 
APOLLO was a randomised, double-blind, placebo-controlled study in which patients were randomly assigned (2:1) to receive patisiran $0.3 \mathrm{mg} / \mathrm{kg}$ or placebo administered by IV infusion q3w for 18 months. ${ }^{6}$ Patients were randomised via an interactive response system and treatment arms were further balanced at entry for Neurologic Impairment Score (NIS), early-onset V30M vs all other variants, and previous TTR stabiliser use. Further details of the randomisation and blinding process are described in the previously published APOLLO protocol (appendix, p 2). Key eligibility criteria for the APOLLO study included being $18-85$ years of age; documented pathogenic TTR variant; diagnosis of ATTRv amyloidosis with polyneuropathy; a NIS of 5-130; and polyneuropathy disability (PND) score of IIIB or lower with adequate liver and renal function. ${ }^{6}$ Patients with prior liver transplantation or who were New York Heart Association (NYHA) class III or IV were excluded. ${ }^{6}$

In the phase 2 OLE, multi-centre, international study, ${ }^{14}$ patients who had previously received and tolerated patisiran in the phase 2 study $\left(\right.$ NCT01961921) ${ }^{17}$ received $0.3 \mathrm{mg} / \mathrm{kg}$ patisiran via IV infusion q3w for 24 months. ${ }^{14}$ Key eligibility criteria included Karnofsky Performance Status $\geq 60 \%$ and adequate liver and renal function. Patients with prior liver transplantation or who were NYHA class $>$ II were excluded. ${ }^{14}$

\section{Procedure}

Patients enrolled in the Global OLE study receive patisiran $0.3 \mathrm{mg} / \mathrm{kg} \mathrm{IV} \mathrm{q3}$. The first dose was administered approximately 3 weeks after the last dose in the parent study, either APOLLO or the phase 2 OLE, to maintain the dosing schedule. Treatment is provided either at the study site or via home infusion by a trained healthcare professional where applicable country and local regulations allowed. All patients receive premedication (appendix, $\mathrm{p} 2$ ) to reduce the potential of infusionrelated reactions (IRRs) and continue to take vitamin A supplementation based on the US recommended daily allowance or, at the discretion of the investigator, the local recommended daily allowance of vitamin A. 
Efficacy endpoints are measured at the study site or through a central assessment site and include assessments of polyneuropathy (mNIS+7); QOL (Norfolk QOL-DN); autonomic symptoms (Composite Autonomic Symptom Score 31 [COMPASS-31]); nutritional status (modified body mass index [mBMI]; $\mathrm{kg} / \mathrm{m}^{2} \times$ albumin level in $\mathrm{g} / \mathrm{L}$ ); disability (Rasch-built Overall Disability Scale [R-ODS]); PND score; familial amyloid polyneuropathy (FAP) stage; motor function (10-metre walk test [10$\mathrm{MWT}$; gait speed; grip strength); and cardiac stress ( $\mathrm{N}$-terminal prohormone of B-type natriuretic peptide [NT-proBNP] levels). Ranges for scored measures are given in the appendix, $p 4$. The outcomes listed above are included in this interim 12-month analysis; however, a full list of outcome measures to be collected during the 5-year study is provided in the appendix, p 5 .

Serum TTR levels are measured before patisiran administration and were recorded at baseline, at month 6, and at each annual visit. Antidrug antibodies (serum immunoglobulin [Ig] G/IgM antibodies specific to $\alpha$-(3-\{[1,2-di(myristyloxy)proponoxy] carbonylamino\}propyl)- $\omega$ methoxy, polyoxyethylene) are evaluated using a validated ELISA method ${ }^{6}$ at month 6 and each annual visit.

AEs are recorded and clinical laboratory testing (haematology, blood chemistry, urinalysis), vital signs, physical examination, Columbia-Suicidality Severity Rating Scale, and ophthalmology testing are being conducted throughout the study. AEs are coded according to the Medical Dictionary for Regulatory Activities Version 18.0, and deaths are adjudicated as described in the appendix, p 6.

\section{Outcomes}

The Global OLE does not have pre-specified primary or secondary outcomes as part of the protocol (appendix, p 2). One-year efficacy outcomes included mean change from parent study baseline or Global OLE enrolment to after 12 months in the Global OLE in mNIS+7, Norfolk QOL-DN, COMPASS31, mBMI, R-ODS, PND score, FAP stage, 10-MWT, grip strength, and NT-proBNP levels. Serum TTR 
levels were measured as a pharmacodynamic outcome. Safety assessments included AE monitoring as well as clinical laboratory testing.

\section{Statistical analysis}

The sample size for this study was not pre-specified; all patients who completed the APOLLO or phase 2 OLE studies could enrol if they met the eligibility criteria. Efficacy analyses included data from patients who completed the 12-month efficacy assessment. Efficacy data are described either as integrated change from parent study baseline to Global OLE 12 months and/or change from Global OLE enrolment to Global OLE 12 months. Safety analyses included data for patients who received $\geq 1$ dose of patisiran up to the data cut-off, including data beyond the 12-month assessment.

In a post hoc analysis, the integrated exposure-adjusted mortality rate (using pooled data for all patisiran-treated patients from the parent and Global OLE studies) was calculated overall and by treatment group as the total number of deaths per total patient-years of exposure $\times 100$. Deaths occurring between the first patisiran dose and up to 90 days after the last dose were included in the calculation. Additional details are described in the appendix, p 2.

Categorical variables were reported as the number and percentage of patients. For continuous variables, mean, median, standard deviation (SD), standard error of the mean (SEM), 95\% confidence intervals (Cls), interquartile range, and range were calculated. No formal significance tests were performed as this study did not include a comparator arm. SAS version 9.4 was used to conduct the statistical analyses. A data monitoring committee was not assigned to oversee this study. This trial is registered as NCT02510261.

\section{Role of the funding source}


Alnylam Pharmaceuticals funded the study and collaborated with authors during study design, collection, analysis, interpretation of data, and drafting/reviewing the article. The corresponding author had full access to all data in the study and final responsibility over the decision to submit for publication.

\section{Results}

Between 13 July 2015 and 21 August 2017, 211/212 patients (figure 1) enrolled at 43 sites in 19 countries. As of the data cut-off (24 September 2018), 34/211 (16\%) patients had withdrawn from the study. Primary reasons for withdrawal (investigator determined) included death (21/211 [10\%]), AEs (9/211 [4\%]), physician decision (2/211 [1\%]), and withdrawal (2/211 [1\%]) (figure 1). The proportion of withdrawals in the APOLLO-placebo group (16/49 [33\%]) was higher than in the APOLLO-patisiran (18/137 [13\%]) and phase 2 OLE patisiran (0/25 [0\%]) groups.

Twelve-month efficacy assessments were available for 189/211 (90\%) patients (126/137 [92\%], 38/49 [78\%], and 25/25 [100\%] patients in the APOLLO-patisiran, APOLLO-placebo, and phase 2 OLE patisiran groups, respectively). Patients had received patisiran for a mean (SD) of 20.5 (8.0) months and had a cumulative drug exposure of 359.6 patient-years (PY); 133/211 (63\%) patients received all planned doses and 49/211 (23\%), 16/211 (8\%), and 13/211 (6\%) patients missed 1, 2 , and $\geq 3$ doses, respectively. A total of 577/6005 (10\%) infusions of patisiran were received at home by $26 / 211(12 \%)$ patients.

At Global OLE enrolment, patients in the APOLLO-placebo group had higher NT-proBNP levels and more severe disease than patients in the APOLLO-patisiran and phase 2 OLE patisiran groups, as shown by mNIS+7, Norfolk QOL-DN, PND scores, COMPASS-31, and R-ODS (table 1). The phase 2 OLE patisiran group had a higher proportion of patients with the V30M genotype and less severe disease at Global OLE enrolment than patients in either APOLLO group. 
The improvement in polyneuropathy with patisiran treatment, demonstrated by a negative change in mean mNIS+7 score relative to APOLLO and phase 2 OLE baseline, was maintained at Global OLE 12 months (mean change [ $95 \% \mathrm{Cl}],-4 \cdot 0[-7 \cdot 7$ to $-0 \cdot 3]$ APOLLO-patisiran; $-4 \cdot 7$ [ -11.9 to 2.4] phase 2 OLE patisiran) (figures $2 A$ and $2 B$ ). The rapid polyneuropathy progression observed among APOLLO-placebo patients halted upon patisiran treatment in the Global OLE, with an improvement in mNIS+7 at Global OLE 12 months from Global OLE enrolment (mean change [95\% $\mathrm{Cl}],-1 \cdot 4[-6 \cdot 2$ to $3 \cdot 5])$. However, mean mNIS +7 score did not return to APOLLO baseline, likely due to the deterioration on placebo during APOLLO (mean change $[95 \% \mathrm{CI}]$ from APOLLO baseline to Global OLE 12 months $+24 \cdot 0[15 \cdot 4-32 \cdot 5])$.

Maintained improvement in QOL, shown by Norfolk QOL-DN, was observed in the APOLLOpatisiran group at Global OLE 12 months relative to APOLLO baseline (mean change [95\% $\mathrm{Cl}]-3 \cdot 9$ [8.1 to 0.3$]$ ) (figure $2 \mathrm{C}$ ). Among APOLLO-placebo patients, patisiran treatment in the Global OLE improved Norfolk QOL-DN (mean change [95\% Cl] from Global OLE enrolment to Global OLE 12 months $-4.5[-9.6$ to 0.7$]$ ), halting the deterioration seen during APOLLO. As with the mNIS+7 score, QOL did not return to APOLLO baseline values in the Global OLE (mean change $[95 \% \mathrm{Cl}]$ from parent baseline to Global OLE 12 months, $+15 \cdot 0[8 \cdot 1-21 \cdot 9])$.

Maintained improvement in autonomic function in the APOLLO-patisiran group (mean change $[95 \% \mathrm{Cl}],-4.0[-6.9$ to $-1 \cdot 1]$ ) and stabilisation in the phase 2 OLE patisiran group (mean change $[95 \% \mathrm{Cl}],+0 \cdot 1[-4 \cdot 2$ to $4 \cdot 4])$, as measured by COMPASS-31, was seen at Global OLE 12 months compared with parent study baselines (figures 2D and 2E). Consistent with worsening disease, patients who received placebo experienced deterioration in autonomic function during APOLLO, but improvement was seen once they switched to patisiran in the Global OLE (mean change [95\% $\mathrm{Cl}$ ] from Global OLE enrolment to Global OLE 12 months -3.7 [ -8.0 to 0.6$])$. Nutritional status (mBMI) was maintained (APOLLO-patisiran and phase 2 OLE patisiran) from parent study baseline or improved (APOLLO-placebo) from Global OLE enrolment (figures 2F and 2G). However, COMPASS-31 
and $\mathrm{mBMI}$ values did not return to APOLLO baseline in the APOLLO-placebo group due to deterioration experienced on placebo.

The R-ODS score declined slightly compared with parent study baseline in both the APOLLOpatisiran and phase 2 OLE patisiran groups (figures $2 \mathrm{H}$ and 2I). However, this decline was modest compared with the substantial worsening observed in the APOLLO-placebo group during APOLLO. Disability among the APOLLO-placebo patients stabilised once they started receiving patisiran.

Compared with parent study baselines, the majority of patients in the APOLLO-patisiran and phase 2 OLE patisiran groups had an improved or stable PND score at Global OLE 12 months (89/148 [60\%] APOLLO-patisiran, 17/27 [63\%] phase 2 OLE patisiran) (appendix, $p$ 7). The majority of patients in the APOLLO-placebo group demonstrated stable or improved scores at Global OLE 12 months after receiving patisiran treatment in the Global OLE. Similar results were observed with FAP stage (appendix, p 7). Additional clinical and functional parameters, including 10-MWT and grip strength, either improved or stabilised at Global OLE 12 months from the initiation of patisiran treatment among the three groups (appendix, p 8).

NT-proBNP levels were stable in both groups previously treated with patisiran from Global OLE enrolment to Global OLE 12 months. In the APOLLO-placebo group, NT-proBNP levels worsened during APOLLO, but improved once patisiran treatment was initiated (appendix, p 8).

Robust, sustained reduction in mean serum TTR levels was observed in the APOLLO-placebo group upon patisiran treatment in the Global OLE, with a mean (SD) percent TTR reduction of $78 \cdot 7 \%$ (17-1\%) at month 6 (appendix, p 19). Serum TTR reductions in APOLLO-patisiran and phase 2 OLE patisiran groups were maintained with continued patisiran in the Global OLE. Antidrug antibody incidence was low $(1 / 211$ patient $[<1 \%]$ at week 26 only) and transient.

Safety outcomes as of the data cut-off of 24 September 2018 are shown in table 2. In total, 204/211 (97\%) patients reported AEs. The majority of AEs were mild or moderate in severity. The 
most common treatment-related AE was mild or moderate IRRs (eg, back pain, flushing, or rash), which occurred in 25/211 (12\%) patients (appendix, p 9); the incidence of IRRs decreased over time. The proportion of patients experiencing IRRs was higher in those newly treated with patisiran in the Global OLE (APOLLO-placebo, 13/49 [27\%]) than those who previously received patisiran (APOLLOpatisiran, 10/137 [7\%]; phase 2 OLE patisiran, 2/25 [8\%]). There were no serious IRRs or discontinuations due to IRRs. IRRs occurred in 4/26 (15\%) patients who had home infusions and were generally mild, transient, and readily managed without interruption of the infusion due to the IRR.

SAEs were reported for $82 / 211$ (39\%) patients and were most frequent among patients in the APOLLO-placebo group (28/49 [57\%]) (table 3). Two out of 211 patients (1\%), both in the APOLLO-placebo group, had SAEs that were considered treatment-related, 1 patient with abdominal discomfort and 1 patient with two events associated with extravasation of study drug and reported as phlebitis, cellulitis, hypotension, bacteraemia, and systemic inflammatory response syndrome. Cardiac AEs and SAEs were reported in 44/211 (21\%) and 31/211 (15\%) patients, respectively; no cardiac AEs were considered related to study drug. Frequencies of cardiac AEs (16/49 [33\%]) and cardiac SAEs (11/49 [22\%]) were higher in the APOLLO-placebo group compared with other groups.

No clinically relevant safety concerns were identified related to hepatic events, renal events, malignancies, ocular events, metabolic events, and thyroid disorders. No clinically relevant changes were observed in laboratory values (including platelet count), vital signs, and physical examination findings (including ophthalmology examinations) during the Global OLE study.

The frequency of deaths in the Global OLE was higher in the APOLLO-placebo group (13/49 [27\%]) than the APOLLO-patisiran (10/137 [7\%]) and phase 2 OLE patisiran (0/25 [0\%]) groups. Causes of death were consistent with the natural history of ATTRv amyloidosis, with most patients who died having known risk factors for poor prognosis (non-V30M genotype, advanced age, advanced disease status, long duration of disease, advanced neuropathic and cardiac involvement) 
and marked disease burden at Global OLE enrolment (17/23 [74\%] patients had PND $\geq$ IIIA, including 14/23 (61\%) PND $\geq 11 \mathrm{IB}$, and 20/23 [87\%] patients had NT-proBNP $\geq 600 \mathrm{pg} / \mathrm{mL}$, including 10/23 [43\%] patients with NT-proBNP $\geq 3000 \mathrm{pg} / \mathrm{mL}$ ). Investigator-reported causes of death ( $\mathrm{n}=1$ for each event unless otherwise specified) include acute myocardial infarction ( $n=3)$, cardiac arrest $(n=3)$, amyloidosis $(n=3)$, acute kidney injury, acute respiratory distress syndrome, acute respiratory failure, arrhythmia, atrial flutter, cardiogenic shock, cardiopulmonary failure, cerebrovascular accident, chronic kidney disease, death (cause unknown), dehydration, electrolyte imbalance, hip fracture, haemorrhagic shock, hypovolaemic shock, neurogenic shock, pancreatitis, and septic shock (appendix, p 6). None of the $23 / 211(11 \%)$ deaths during the Global OLE reporting period were considered treatment-related by investigators.

Across the three studies (phase 2 OLE, APOLLO, and Global OLE), a total of 224 patients received $\geq 1$ dose of patisiran, with some patients receiving $\geq 4$ years of patisiran treatment. Overall mean (SD) exposure was 34.0 months (14.5) with 104/224 (46\%) patients treated for $\geq 3$ years and $35 / 224$ (16\%) for $\geq 4$ years. As of the data cut-off, the overall exposure-adjusted mortality rate for all patisiran-treated patients was $4 \cdot 8$ per $100 \mathrm{PY}(95 \% \mathrm{Cl} 3 \cdot 3-6 \cdot 7)$, based on 30 deaths and 629.4 PY cumulative exposure (appendix, p 10). In a post hoc analysis, the exposure-adjusted mortality rate was lowest for patients from the phase 2 OLE, who were treated the longest and from the earliest stage of disease, and lower in APOLLO-patisiran compared with APOLLO-placebo patients (appendix, p 10).

In the APOLLO study, the exposure-adjusted mortality rate was lower in patients who received patisiran (3.2 per $100 \mathrm{PY}[95 \% \mathrm{Cl} 1 \cdot 4-6 \cdot 2])$ than placebo $(6 \cdot 2$ per $100 \mathrm{PY}[95 \% \mathrm{Cl} 2 \cdot 5-12 \cdot 7])$. A post hoc analysis to account for the effect of important imbalances between treatment groups showed that exposure-adjusted mortality rates remained consistently lower in patients who received patisiran versus placebo (appendix, p 20). 


\section{Discussion}

Patients in this study represent those with the longest treatment duration with an RNAi therapeutic to date. The Global OLE enrolled patients with ATTRv amyloidosis with polyneuropathy with a wide range of disease severity who had previously received either patisiran or placebo in APOLLO, or patisiran in the phase 2 OLE study. The beneficial effects of patisiran on polyneuropathy, QOL, autonomic symptoms, nutritional status, motor function, disability, and cardiac stress were sustained at Global OLE 12 months, demonstrating maintenance of patisiran efficacy with continued treatment. Additionally, patisiran continued to demonstrate an acceptable safety profile.

Patients who received placebo during APOLLO had accumulated greater disease burden compared with those who had received patisiran. Despite disease progression in APOLLO, these patients exhibited stabilisation or improvement compared with Global OLE enrolment in mean mNIS+7, Norfolk QOL-DN, COMPASS-31, mBMI, and NT-proBNP levels following 12 months of patisiran treatment in the Global OLE. However, their neurological disability and mortality rate remained higher than in patients who received patisiran in the parent studies, underscoring the importance of treatment at the earliest disease stage possible. This strategy is also supported by the observation that patients from the phase 2 OLE, who had less advanced disease at patisiran initiation and were treated for the longest time, did not experience disease progression across a number of measures.

Consistent with patisiran's treatment hypothesis, reduction in serum TTR levels with patisiran treatment was maintained at Global OLE 12 months for the APOLLO-patisiran and phase 2 OLE patisiran groups and was also observed in the APOLLO-placebo group after initiation of patisiran treatment.

The patisiran safety profile remained consistent with previous studies. ${ }^{6,14,17}$ During the Global OLE, IRRs were more frequently reported in the APOLLO-placebo group compared with the 
APOLLO-patisiran and phase 2 OLE patisiran groups which was expected, as IRRs tend to decrease in frequency with subsequent infusions.

In the Global OLE, deaths occurred most frequently in the APOLLO-placebo group, which had the greatest disease burden at Global OLE enrolment and could be considered at an advanced stage of the disease (eg, higher PND scores, higher NYHA class scores, worse mNIS+7 scores, worse Norfolk QOL-DN scores, and higher NT-proBNP levels). As more severe disease is associated with mortality, this higher death rate is expected despite the positive effects of patisiran in preventing further progression. The mortality rate was lowest in the phase 2 OLE patisiran group, which included patients with the least advanced disease at baseline, further supporting the need for early treatment. None of the deaths reported were considered to be treatment related.

The exposure-adjusted mortality rate observed at interim analysis across all patisirantreated patients from APOLLO, phase 2 OLE, and Global OLE (4.8 deaths/100 PY) was at the lower end of the expected range based on disease progression of ATTR amyloidosis estimated from natural history studies and placebo data from clinical trials (range 7-29 deaths/100 PY), especially for those who started patisiran treatment early in the disease course..$^{9,12,18-20}$ This corroborates findings from APOLLO, which demonstrated lower exposure-adjusted mortality rates with patisiran versus placebo. Despite accounting for non-V30M genotype and elevated NT-proBNP, known risk factors for mortality, the point estimates of the exposure-adjusted mortality rate were lower in the patisiran group compared with the placebo group in the APOLLO study. ${ }^{16,21-23}$ These data, when coupled with the favourable safety data reported with inclisiran (over 2700 PY of exposure in patients with cardiovascular disease) and the FDA approval of givosiran, continue to support the safety and potential of RNAi therapeutics. ${ }^{24,25}$

The Global OLE encompasses a large number of patients with a broad spectrum of disease from many countries in order to assess the efficacy and safety of long-term patisiran treatment in patients with ATTRv amyloidosis with polyneuropathy. However, this report is an interim analysis 
and is potentially limited by the need to evaluate whether the clinical benefits are maintained to the end of the study. The population for this study was self-selected from previous patisiran studies and therefore open to selection bias. However, it should be noted that potential bias was minimised by the very high retention rate of eligible patients (211/212 [99.5\%]). Other limitations include the unblinded nature of an open-label study (which could potentially influence patient responses to assessments), fewer patients in the APOLLO-placebo group compared with the APOLLO-patisiran group (due to the 2:1 randomisation in APOLLO), and the lack of a placebo group to compare data against. Additionally, the results are descriptive and no inferential analyses were performed.

The overall findings of the 12-month interim data from the Global OLE study underscore the importance of patisiran treatment early in the disease course to halt or reverse the progression of polyneuropathy, dysautonomia, disability, malnutrition, and QOL impairment. Delay in treatment may negatively impact outcomes, including survival, and therefore the data here along with future and ongoing real-world studies in this disease aim to further emphasise the role of early diagnosis and treatment.

\section{Research in context}

\section{Evidence before this study}

We searched PubMed, www.clinicaltrials.gov, and abstracts presented at international congresses (International Society of Amyloidosis, European Meetings on transthyretin-mediated amyloidosis for Doctors and Patients, International Congress on Neuromuscular Diseases, and Peripheral Nerve Society from 1 July 2015 to 30 June 2020 to identify publications describing the burden of hereditary transthyretin (ATTRv) amyloidosis, and clinical data for treatments investigated for this disease. The following search terms were used: 'ATTRv amyloidosis', 'hATTR amyloidosis', 'familial amyloid 
polyneuropathy', 'familial amyloid cardiomyopathy', 'FAP', and 'FAC'. Publications describing individual case studies or preclinical investigations of pharmacotherapies were excluded. The existing evidence indicates that ATTRv amyloidosis is a progressively debilitating disease, associated with multisystem involvement, for which only a limited number of therapies are approved or available. Of these therapies, patisiran is an RNA interference (RNAi) therapeutic that has been shown to reduce levels of the disease-causing transthyretin (TTR) protein. Patisiran demonstrated a positive benefit-risk profile in a previous 18-month phase 3 study (APOLLO; NCT01960348) in patients with ATTRv amyloidosis with polyneuropathy.

\section{Added value of this study}

To our knowledge, this 12-month interim analysis of an open-label extension (OLE) study reports the longest duration of treatment with an RNAi therapeutic, patisiran, in patients with ATTRv amyloidosis with polyneuropathy. The data reported here show that treatment with patisiran led to improvement or sustained stability in measures of polyneuropathy (modified Neuropathy Impairment Score +7), quality of life (Norfolk QOL-Diabetic Neuropathy questionnaire), autonomic function (Composite Autonomic Symptom Score 31), disability (Rasch-built Overall Disability Scale), and nutritional status (modified body mass index) compared with their treatment-naïve baseline values. Overall, these findings indicate that halting or reversing progression of polyneuropathy is achievable and can be maintained in patients with ATTRv amyloidosis with polyneuropathy.

The study also showed the acceptable safety profile of long-term patisiran treatment in patients with ATTRv amyloidosis with polyneuropathy. The overall mortality rate on patisiran is at the lower end of the expected range based on disease natural history data.

\section{Implications of all the available evidence}


The 12-month interim data show that efficacy and safety of patisiran is consistent with results previously reported in the phase 2 OLE and APOLLO studies. The long-term benefits beyond this interim report require further follow-up.

\section{Contributors}

MTSw performed the literature search. DA, TC, MTSw, and MTW contributed to the conception and design of the study. EA, EB, MTSW, and MTW helped to analyse the data. IMC, JJW, and MW-C assisted with data collection. EA, JDG, and MSS assisted with figures and writing. JV contributed to data analysis and writing. DA, SA-D, SA, JLB, THB, TC, AD, AG-D, AVK, TK, IALL, EM, MMM, VP-B, MP, DQ, HHS, MTSW, MU, MTW, EB, and JW all contributed to data collection, figures, and writing. JJW was also responsible for medical monitoring of the clinical trial. All authors helped to interpret the data and critically revise the publication, are accountable for the accuracy and integrity of the publication and provided final approval to submit for publication.

\section{Declaration of interests}

DA reports consultancy fees and institutional grants from Alnylam Pharmaceuticals and Pfizer Inc. and symposium honoraria from Pfizer Inc. outside the submitted work. SA-D reports personal fees from Alnylam Pharmaceuticals outside the submitted work. SA reports grants from Alnylam Pharmaceuticals and Pfizer Inc. outside the submitted work. JLB acknowledges study investigator and coordination time and hospital services compensation from Alnylam Pharmaceuticals for the work under consideration; personal fees for a visiting Professor presentation from Alnylam Pharmaceuticals, advisory committee from Akcea Therapeutics, study investigator and coordinator compensation from Pfizer Inc. and scientific advisory board fees from Intellia Therapeutics and Corino Therapeutics outside the submitted work. THB reports grants and personal fees from Alnylam Pharmaceuticals during the conduct of the study; grants and personal fees from lonis Pharmaceuticals and personal fees from Akcea Therapeutics and Pfizer Inc. outside the submitted 
work. TC reports financial support to attend scientific meetings from Pfizer Inc. and personal fees from Alnylam Pharmaceuticals and Akcea Therapeutics outside the submitted work. IMC reports primary investigator fees from Alnylam Pharmaceuticals during the conduct of the study and consultancy fees from Pfizer Inc and lonis Pharmaceuticals and primary investigator fees from lonis Pharmaceuticals outside the submitted work. AD acknowledges research funding from Pfizer Inc., Celgene Corporation, Alnylam Pharmaceuticals, Takeda Pharmaceuticals, Akcea Therapeutics, and Prothena Corporation, advisory board fees from Caelum Biosciences, and institutional funding for advisory board participation from Intellia Therapeutics outside the submitted work. JDG reports institutional grants from Alnylam Pharmaceuticals during the conduct of the study and honoraria for an expert advisory board from Alnylam Pharmaceuticals outside the submitted work. AG-D reports consultancy fees from Alnylam Pharmaceuticals and Pfizer Inc. outside the submitted work. AVK reports honoraria, fees for lectures and speakers' bureaus. IALL acknowledges personal fees, nonfinancial support, and other support outside the submitted work. EM reports honorarium paid to her institution (Mayo Clinic) from Alnylam Pharmaceuticals for symposium speaking. MMM reports pending honorarium for poster presentation and principal investigator fees from Alnylam Pharmaceuticals during the conduct of the study; speaker and advisory board fees from Alnylam Pharmaceuticals, Akcea Therapeutics, and Pfizer Inc., and non-financial support from Alnylam Pharmaceuticals outside the submitted work. VP-B reports principal investigator and advisory board fees from Alnylam Pharmaceuticals and principal investigator and symposium speaker fees from Ionis/Akcea Therapeutics, during the conduct of the study. MP acknowledges consultancy and principal investigator fees from Alnylam Pharmaceuticals in relation to this work and consultancy and principal investigator fees from Alnylam Pharmaceuticals and Ionis Pharmaceuticals, and consultancy fees from Eidos and Pfizer Inc. outside the submitted work. DQ reports grants, personal fees and non-financial support from Alnylam Pharmaceuticals; grants and non-financial support from Pfizer and Cytokinetics; and grants from lonis, Momenta, and Argenx during the conduct of the study. MSS reports consultancy fees and symposium and advisory board participation honoraria 
from Alnylam Pharmaceuticals and Pfizer Inc. outside the submitted work. MU acknowledges personal fees and non-financial support for advisory board participation, travel, and speaking from Alnylam Pharmaceuticals and Pfizer Inc. outside the submitted work. MW-C reports honorarium from NHI, Prothena Corporation, FoldRx, Ionis Pharmaceuticals, Pfizer Inc., Alnylam Pharmaceuticals, PTC, and Genzyme for travel expenses related to presentations at medical meetings, for acting as a principal investigator in clinical trials, and as a consultant. JW reports advisory board and lecture fees from Alnylam Pharmaceuticals, Pfizer Inc., and Akcea Therapeutics outside the submitted work. TK and HHS have nothing to disclose. EA, MTSW, JV, and MTW are employees of Alnylam Pharmaceuticals; in addition, EA, MTSw, JV, and MTW have stock options and EA, MTSw, JV, and MTW have stocks. EB and JJW are former employees of Alnylam Pharmaceuticals and had stock options.

\section{Acknowledgements}

This study was funded by Alnylam Pharmaceuticals Inc., USA. The authors would like to thank the patients and their families for their valued contribution to this study. The authors would also like to thank the patisiran Global OLE study group listed in the appendix, $\mathrm{p} 11$.

The authors would like to thank Jennifer LS Willoughby, PhD, Katherine Alfond, PharmD, RPh, and Anastasia McManus, PharmD, RPh, of Alnylam Pharmaceuticals Inc., Cambridge, USA for editorial assistance. The authors acknowledge the medical writing services provided by Ed Childs, PhD, of Adelphi Communications Ltd, Macclesfield, UK, in accordance with the Good Publication Practice (GPP3) guidelines, funded by Alnylam Pharmaceuticals Inc.

\section{Data sharing}

The datasets generated and analysed during the current study are not publicly available.

\section{References}


1. Adams D, Coelho T, Obici L, et al. Rapid progression of familial amyloidotic polyneuropathy: a multinational natural history study. Neurology 2015; 85: 675-82.

2. Mohty D, Damy T, Cosnay P, et al. Cardiac amyloidosis: updates in diagnosis and management. Arch Cardiovasc Dis 2013; 106: 528-40.

3. Adams D, Koike H, Slama M, Coelho T. Hereditary transthyretin amyloidosis: a model of medical progress for a fatal disease. Nat Rev Neurol 2019; 15: 387-404.

4. Rapezzi C, Quarta CC, Obici L, et al. Disease profile and differential diagnosis of hereditary transthyretin-related amyloidosis with exclusively cardiac phenotype: an Italian perspective. Eur Heart J 2013; 34: 520-8.

5. Coelho T, Maurer MS, Suhr OB. THAOS - The Transthyretin Amyloidosis Outcomes Survey: initial report on clinical manifestations in patients with hereditary and wild-type transthyretin amyloidosis. Curr Med Res Opin 2013; 29: 63-76.

6. Adams D, Gonzalez-Duarte A, O'Riordan WD, et al. Patisiran, an RNAi therapeutic, for hereditary transthyretin amyloidosis. N Engl J Med 2018; 379: 11-21.

7. Benson $\mathrm{MD}$, Waddington-Cruz $\mathrm{M}$, Berk JL, et al. Inotersen treatment for patients with hereditary transthyretin amyloidosis. N Engl J Med 2018; 379: 22-31.

8. Swiecicki PL, Zhen DB, Mauermann ML, et al. Hereditary ATTR amyloidosis: a singleinstitution experience with 266 patients. Amyloid 2015; 22: 123-31.

9. Sattianayagam PT, Hahn AF, Whelan CJ, et al. Cardiac phenotype and clinical outcome of familial amyloid polyneuropathy associated with transthyretin alanine 60 variant. Eur Heart J 2012; 33: $1120-7$.

10. Ando Y, Coelho T, Berk JL, et al. Guideline of transthyretin-related hereditary amyloidosis for clinicians. Orphanet J Rare Dis 2013; 8: 31.

11. Coelho T, Maia LF, Martins da Silva A, et al. Tafamidis for transthyretin familial amyloid polyneuropathy: a randomized, controlled trial. Neurology 2012; 79: 785-92. 
12. Berk JL, Suhr OB, Obici L, et al. Repurposing diflunisal for familial amyloid polyneuropathy: a randomized clinical trial. JAMA 2013; 310: 2658-67.

13. Coelho T, Adams D, Silva A, et al. Safety and efficacy of RNAi therapy for transthyretin amyloidosis. N Engl J Med 2013; 369: 819-29.

14. Coelho T, Adams D, Conceição I, et al. A phase II, open-label, extension study of long-term patisiran treatment in patients with hereditary transthyretin-mediated (hATTR) amyloidosis. Orphanet J Rare Dis 2020; 15.

15. González-Duarte A, Berk JL, Quan D, et al. Analysis of autonomic outcomes in APOLLO, a phase III trial of the RNAi therapeutic patisiran in patients with hereditary transthyretin-mediated amyloidosis. J Neurol 2020; 267: 703-12.

16. Solomon SD, Adams D, Kristen A, et al. Effects of patisiran, an RNA interference therapeutic, on cardiac parameters in patients with hereditary transthyretin-mediated amyloidosis. Circulation 2019; 139: 431-43.

17. Suhr OB, Coelho T, Buades J, et al. Efficacy and safety of patisiran for familial amyloidotic polyneuropathy: a phase II multi-dose study. Orphanet J Rare Dis 2015; 10: 109.

18. Ruberg FL, Maurer MS, Judge DP, et al. Prospective evaluation of the morbidity and mortality of wild-type and V122I mutant transthyretin amyloid cardiomyopathy: the Transthyretin Amyloidosis Cardiac Study (TRACS). Am Heart J 2012; 164: 222-8 e1.

19. Arruda-Olson AM, Zeldenrust SR, Dispenzieri A, et al. Genotype, echocardiography, and survival in familial transthyretin amyloidosis. Amyloid 2013; 20: 263-8.

20. Maurer MS, Schwartz JH, Gundapaneni B, et al. Tafamidis treatment for patients with transthyretin amyloid cardiomyopathy. N Engl J Med 2018; 379: 1007-16.

21. Damy $T$, Costes B, Hagege AA, et al. Prevalence and clinical phenotype of hereditary transthyretin amyloid cardiomyopathy in patients with increased left ventricular wall thickness. Eur Heart J 2016; 37: 1826-34. 
22. Kristen AV, Maurer MS, Rapezzi C, et al. Impact of genotype and phenotype on cardiac biomarkers in patients with transthyretin amyloidosis - Report from the Transthyretin Amyloidosis Outcome Survey (THAOS). PLoS One 2017; 12: e0173086.

23. Klaassen SHC, Tromp J, Nienhuis HLA, et al. Frequency of and prognostic significance of cardiac involvement at presentation in hereditary transthyretin-derived amyloidosis and the value of N-terminal pro-b-type natriuretic peptide. Am J Cardiol 2018; 121: 107-12.

24. Wright RS, Kallend D, Leiter LA, et al. ORION: a pooled analysis of Phase III studies of inclisiran. American College of Cardiology (ACC); 2020 28-30 March; Virtual meeting, presentation available from: https://www.acc.org/education-and-meetings/image-and-slide-gallery/mediadetail?id=73e76c8923b14790bac5e90f39b5b909; 2020.

25. Alnylam Pharmaceuticals Inc. US prescribing information: GIVLAARI ${ }^{\mathrm{TM}}$ (givosiran) injection, for subcutaneous use. 2019.

https://www.accessdata.fda.gov/drugsatfda_docs/label/2019/0212194s000lbl.pdf (accessed). 


\section{Figure legends}

Figure 1: Patient disposition

$\mathrm{AE}=$ adverse event. $\mathrm{OLE}=$ open-label extension.

Figure 2: Integrated changes in: $\mathrm{mNIS}+7$ from (A) APOLLO and (B) the phase 2 OLE and the Global OLE;

(C) Norfolk-QOL-DN from APOLLO and the Global OLE; COMPASS-31 from (D) APOLLO and (E) the phase 2 OLE and the Global OLE; mBMI from (F) APOLLO and (G) the phase 2 OLE and the Global OLE; and in R-ODS from (H) APOLLO and (I) the phase 2 OLE and the Global OLE

For APOLLO patients initiating alternative ATTRv amyloidosis treatment, mNIS+7 and Norfolk QOL-DN assessments after alternative treatment are treated as missing. Norfolk QOL-DN was not administered in the phase 2 OLE and therefore change over time was not evaluated. ATTRv=hereditary transthyretin. $\mathrm{Cl}=$ confidence interval. COMPASS-31=Composite Autonomic Symptom Score 31. mBMI=modified bodyindex. mNIS+7=modified Neuropathy Impairment Score +7. Norfolk QOL-DN=Norfolk Quality of LifeDiabetic Neuropathy questionnaire. OLE=open-label extension. R-ODS=Rasch-built Overall Disability Scale. "APOLLO-placebo: received placebo in APOLLO and started patisiran for the first time in the Global OLE. ${ }^{\dagger}$ APOLLO-patisiran: received patisiran for 18 months in APOLLO and continued to receive patisiran in the Global OLE. ${ }^{\ddagger}$ Phase 2 OLE patisiran: received patisiran for 24 months and continued to receive patisiran in the Global OLE. 
Figure 1

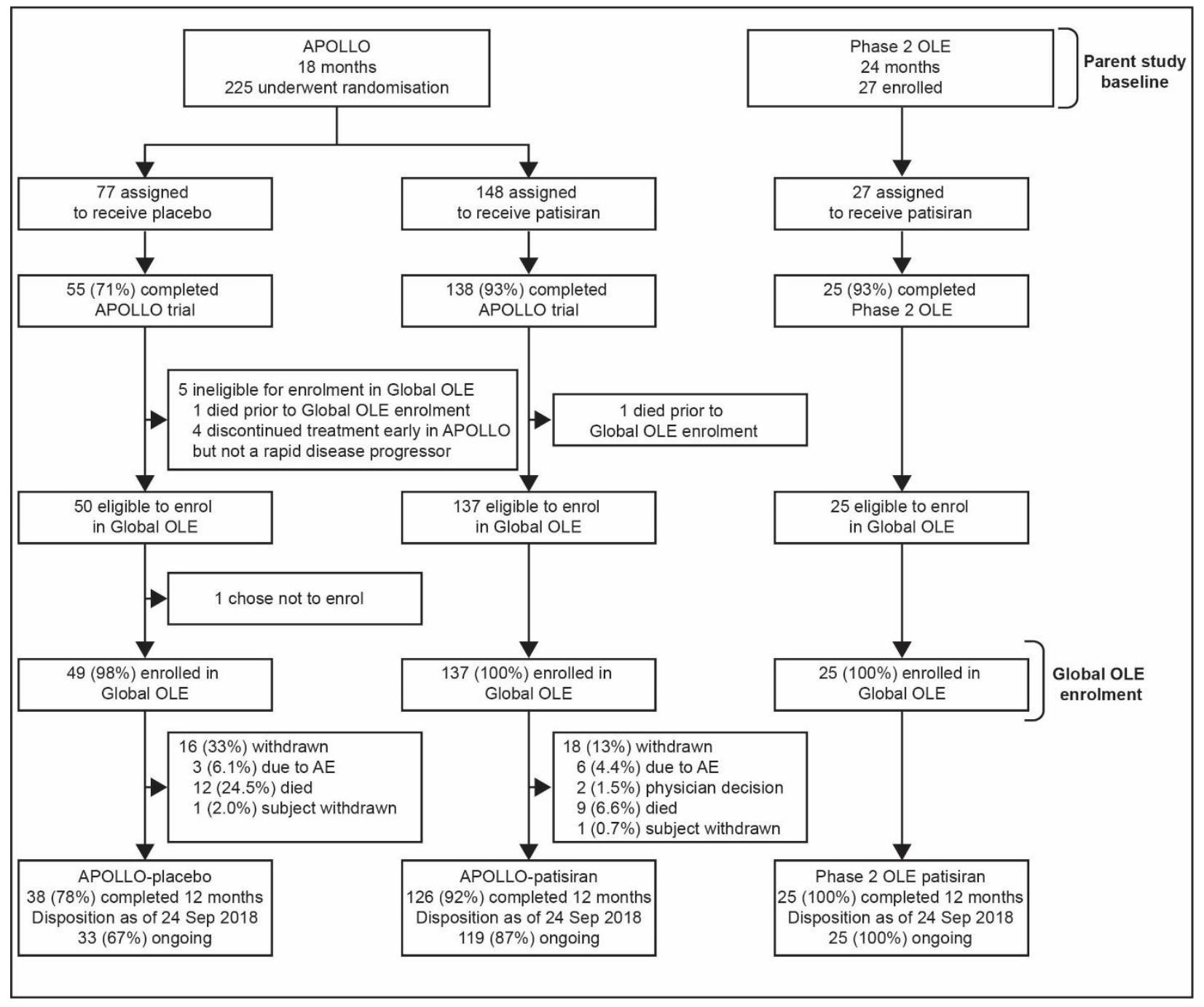


Figure 2
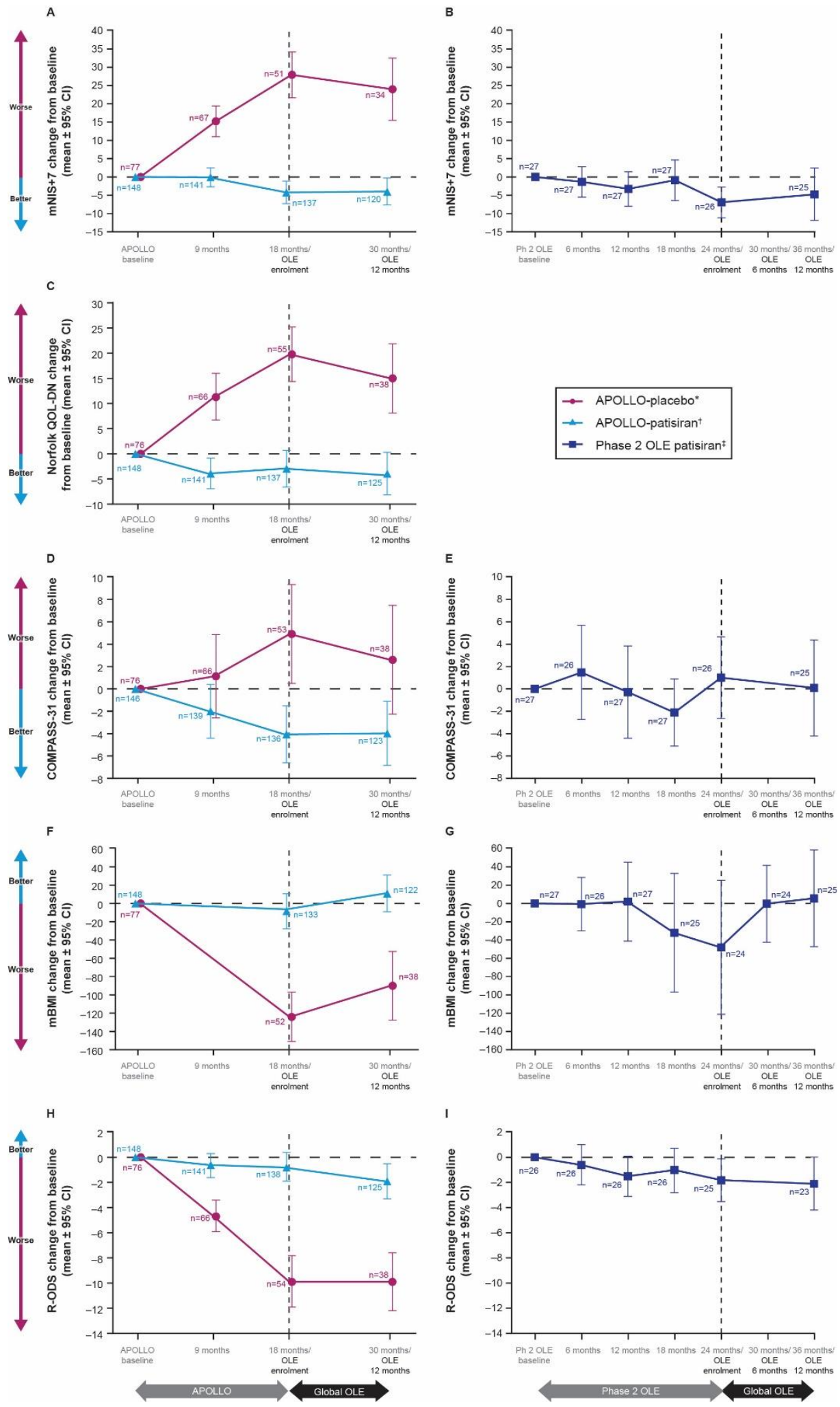


\begin{tabular}{|c|c|c|c|c|}
\hline Parameter & $\begin{array}{l}\text { APOLLO- } \\
\text { placebo } \\
(n=49)\end{array}$ & $\begin{array}{l}\text { APOLLO- } \\
\text { patisiran } \\
(n=137)\end{array}$ & $\begin{array}{l}\text { Phase } 2 \text { OLE } \\
\text { patisiran } \\
(n=25)\end{array}$ & $\begin{array}{c}\text { Global OLE } \\
\text { total } \\
(n=211)\end{array}$ \\
\hline Age, years, mean (SD) & $63 \cdot 5(11 \cdot 0)$ & $61 \cdot 0(12 \cdot 1)$ & $58 \cdot 5(15 \cdot 1)$ & $61 \cdot 3(12 \cdot 3)$ \\
\hline \multicolumn{5}{|l|}{ Sex, n (\%) } \\
\hline Male & $37 / 49(76)$ & $102 / 137(74)$ & $17 / 25(68)$ & $156 / 211(74)$ \\
\hline Female & $12 / 49(24)$ & $35 / 137(26)$ & $8 / 25(32)$ & $55 / 211(26)$ \\
\hline \multicolumn{5}{|l|}{ Ethnicity, $n(\%)^{*}$} \\
\hline Asian & $14 / 49(29)$ & 23/137 (17) & $0 / 25(0)$ & $37 / 211(18)$ \\
\hline Black & $0 / 49(0)$ & 4/137 (3) & $0 / 25(0)$ & $4 / 211(2)$ \\
\hline White & $34 / 49$ (69) & $107 / 137(78)$ & $25(100)$ & $166 / 211(79)$ \\
\hline Other & $0 / 49(0)$ & $1 / 137(1)$ & $0 / 25(0)$ & $1 / 211(<1)$ \\
\hline$>1$ race & $0 / 49(0)$ & $2 / 137(1)$ & $0 / 25(0)$ & $2 / 211(1)$ \\
\hline Missing & $1 / 49(2)$ & $0 / 137(0)$ & $0 / 25(0)$ & $1 / 211(<1)$ \\
\hline \multicolumn{5}{|l|}{ Region $^{\dagger}, \mathrm{n}(\%)$} \\
\hline North America & $5 / 49(10)$ & $34 / 137(25)$ & $1 / 25(4)$ & $40 / 211(19)$ \\
\hline
\end{tabular}




\begin{tabular}{|c|c|c|c|c|}
\hline Western Europe & $26 / 49(53)$ & $61 / 137(45)$ & $23 / 25(92)$ & $110 / 211(52)$ \\
\hline Rest of world & $18 / 49(37)$ & $42 / 137(31)$ & $1 / 25(4)$ & $61 / 211(29)$ \\
\hline \multicolumn{5}{|l|}{ Time since ATTRv amyloidosis diagnosis, years, median (IQR) } \\
\hline To entry into Global OLE & $2 \cdot 8(2 \cdot 0,5 \cdot 4)$ & $3 \cdot 0(2 \cdot 1,4 \cdot 2)$ & $4 \cdot 8(4 \cdot 0,5 \cdot 6)$ & $3 \cdot 4(2 \cdot 2,5 \cdot 0)$ \\
\hline To time of first patisiran dose $e^{\ddagger}$ & $2 \cdot 9(2 \cdot 1,5 \cdot 5)$ & $1 \cdot 4(0 \cdot 6,2 \cdot 7)$ & $2 \cdot 7(1 \cdot 9,3 \cdot 5)$ & $2 \cdot 1(1 \cdot 0,3 \cdot 5)$ \\
\hline \multicolumn{5}{|l|}{ Genotype, n (\%) } \\
\hline V30M & $24 / 49(49)$ & $56 / 137(41)$ & $18 / 25(72)$ & $98 / 211(46)$ \\
\hline Non-V30M & $25 / 49(51)$ & $81 / 137(59)$ & $7 / 25(28)$ & $113 / 211(54)$ \\
\hline Concurrent TTR tetramer stabiliser use ${ }^{\S}, \mathrm{n}(\%)$ & $2 / 49(4)$ & $0 / 137(0)$ & $13 / 25(52)$ & $15 / 211(7)$ \\
\hline \multicolumn{5}{|l|}{ PND score, $n(\%)$} \\
\hline $0:$ no symptoms & $0 / 49(0)$ & $1 / 137(1)$ & $0 / 25(0)$ & $1 / 211(<1)$ \\
\hline I: preserved walking, sensory disturbances & $7 / 49(14)$ & $32 / 137(23)$ & $10 / 25(40)$ & $49 / 211(23)$ \\
\hline II: impaired walking but can walk without stick/crutch & $9 / 49(18)$ & $36 / 137(26)$ & $13 / 25(52)$ & $58 / 211(27)$ \\
\hline IIIA/B: walk with 1 or 2 sticks/crutches & $25 / 49(51)$ & $60 / 137(44)$ & $2 / 25(8)$ & $87 / 211(41)$ \\
\hline IV: confined to wheelchair or bedridden & $8 / 49(16)$ & $8 / 137(6)$ & $0 / 25(0)$ & $16 / 211(8)$ \\
\hline NIS score, median (IQR) ${ }^{\prime \prime}$ & $81(46,116)$ & $61(27,92)$ & $23(14,54)$ & $62(27,93)$ \\
\hline
\end{tabular}




\begin{tabular}{|c|c|c|c|c|}
\hline mNIS+7 score, median (IQR) ${ }^{* *}$ & $94(76,136)$ & $71(39,105)$ & $40(26,57)$ & $76(40,108)$ \\
\hline Norfolk QOL-DN total score, median (IQR) ${ }^{+\dagger}$ & $78(54,91)$ & $55(30,84)$ & $N / A^{\ddagger \ddagger}$ & $60(35,85)$ \\
\hline R-ODS, median (IQR) $)^{\S \S}$ & $18(10,30)$ & $31(20,41)$ & $39(30,45)$ & $29(18,40)$ \\
\hline 10-MWT (m/s), median (IQR) & $0.6(0 \cdot 2,0 \cdot 8)$ & $0.9(0.5,1.2)$ & $1 \cdot 3(1 \cdot 0,1 \cdot 5)$ & $0 \cdot 8(0.5,1 \cdot 2)$ \\
\hline COMPASS-31, median (IQR) $\left.\right|^{\prime \prime I I}$ & $36(19,45)$ & $23(11,37)$ & $11(6,24)$ & $24(11,40)$ \\
\hline $\mathrm{mBMI}^{* * *}$, median (IQR) & $864(721,1007)$ & $982(841,1104)$ & $974(916,1095)$ & $964(813,1094)$ \\
\hline \multicolumn{5}{|l|}{ NYHA classification, n (\%) } \\
\hline I: no symptoms & $22 / 49(45)$ & $67 / 137(49)$ & $19 / 25(76)$ & $108 / 211(51)$ \\
\hline II: symptoms with ordinary physical activity & $21 / 49(43)$ & $59 / 137(43)$ & $4 / 25(16)$ & $84 / 211(40)$ \\
\hline III: symptoms with less than ordinary physical activity & $4 / 49(8)$ & $9 / 137(7)$ & $2 / 25(8)$ & $15 / 211(7)$ \\
\hline IV: symptoms at rest & $2 / 49(4)$ & $2 / 137(1)$ & $0 / 25(0)$ & $4 / 211(2)$ \\
\hline NT-proBNP, pg/mL, median (IQR) & $868(257,2269)$ & $375(132,1147)$ & $166(32,307)$ & $376(132,1378)$ \\
\hline
\end{tabular}

Table 1: Patient demographics and disease characteristics at Global OLE enrolment

Bold text highlights specific baseline difference between groups. 10-MWT=10-metre walk test. ATTRv=hereditary transthyretin. COMPASS-31=Composite Autonomic Symptom

Score-31. FAP=familial amyloid polyneuropathy. mBMI=modified body mass index. IQR=interquartile range. mNIS+7=modified Neuropathy Impairment Score+7. NIS=Neuropathy Impairment Score. Norfolk QOL-DN=Norfolk Quality of Life-Diabetic Neuropathy questionnaire. NT-proBNP=N-terminal prohormone of B-type natriuretic peptide. NYHA=New York Heart Association. OLE=open-label extension. PND=polyneuropathy disability. R-ODS=Rasch-built Overall Disability Scale. SD=standard deviation. TTR=transthyretin. *Race 
was reported by patients. ${ }^{+}$North America: USA, Canada; Western Europe: Germany, Spain, France, United Kingdom, Italy, Netherlands, Portugal, Sweden; Rest of world: Eastern Europe: Bulgaria, Cyprus, Turkey; Asia: Japan, Korea, Taiwan; Central and South America: Mexico, Argentina, Brazil. ${ }^{\ddagger}$ First dose of patisiran in the parent study (APOLLO-patisiran and phase 2 OLE groups), or in the Global OLE study (APOLLO-placebo group). §Use of tafamidis or diflunisal for at least 2 weeks within the first month following first dose in the Global OLE. IIRange 0-244: maximum impairment, 244. ${ }^{* *}$ Range 0-304: maximum impairment, 304. ${ }^{+\dagger}$ Range -4 to 136 : lowest QOL, 136. ${ }^{\ddagger \ddagger}$ Norfolk QOL-DN was not collected in the phase 2 OLE study. ${ }^{\S \S}$ Range 0-48: highest disability, 0. ${ }^{\prime \prime l}$ Range 0-100: maximum impairment, $100 .{ }^{* * *} \mathrm{mBMI}\left(\mathrm{kg} / \mathrm{m}^{2}\right) \times$ albumin $(\mathrm{g} / \mathrm{L})$. 


\begin{tabular}{|c|c|c|c|c|}
\hline & $\begin{array}{l}\text { APOLLO- } \\
\text { placebo } \\
(n=49)\end{array}$ & $\begin{array}{l}\text { APOLLO- } \\
\text { patisiran } \\
\text { (n=137) }\end{array}$ & $\begin{array}{l}\text { Phase } 2 \text { OLE } \\
\text { patisiran } \\
(n=25)\end{array}$ & $\begin{array}{l}\text { Global OLE total } \\
\qquad(\mathrm{n}=\mathbf{2 1 1})\end{array}$ \\
\hline $\begin{array}{l}\text { Months of patisiran exposure in Global OLE: mean } \\
\text { (SD) [range] }\end{array}$ & $\begin{array}{l}17 \cdot 2(8 \cdot 8) \\
{[1 \cdot 3-33 \cdot 8]}\end{array}$ & $\begin{array}{l}19 \cdot 8(7 \cdot 0) \\
{[1 \cdot 3-39 \cdot 0]}\end{array}$ & $\begin{array}{l}30 \cdot 5(2 \cdot 1) \\
{[23 \cdot 0-34 \cdot 5]}\end{array}$ & $\begin{array}{l}20 \cdot 5(8 \cdot 0) \\
{[1 \cdot 3-39 \cdot 0]}\end{array}$ \\
\hline Cumulative number of doses given & 1167 & 3784 & 1054 & 6005 \\
\hline Death*, n(\%) & $13 / 49(27)$ & $10 / 137(7)^{\dagger}$ & $0 / 25(0)$ & $23 / 211(11)$ \\
\hline AEs, n (\%) & & & & \\
\hline $\mathrm{AE}$ & $48 / 49(98)$ & $131 / 137(96)$ & $25 / 25(100)$ & $204 / 211(97)$ \\
\hline Severe AE & $23 / 49(47)$ & $35 / 137(26)$ & $3 / 25(12)$ & $61 / 211(29)$ \\
\hline Serious AE & $28 / 49(57)$ & $48 / 137(35)$ & $6 / 25(24)$ & $82 / 211$ (39) \\
\hline AE leading to study withdrawal & $15 / 49(31)$ & $11 / 137(8)$ & $0 / 25(0)$ & $26 / 211(12)$ \\
\hline Common $\mathrm{AEs} \geq 10 \%$ of patients, $\mathrm{n}(\%)$ & & & & \\
\hline Diarrhoea & $18 / 49(37)$ & $21 / 137(15)$ & $2 / 25(8)$ & $41 / 211(19)$ \\
\hline Peripheral oedema & $12 / 49(24)$ & $20 / 137(15)$ & $4 / 25(16)$ & $36 / 211(17)$ \\
\hline Urinary tract infection & $12 / 49(24)$ & $19 / 137(14)$ & $3 / 25(12)$ & $34 / 211(16)$ \\
\hline Fall & $7 / 49(14)$ & 20/137 (15) & $1 / 25(4)$ & $28 / 211(13)$ \\
\hline Nasopharyngitis & $6 / 49(12)$ & $17 / 137(12)$ & $5 / 25(20)$ & $28 / 211(13)$ \\
\hline Cough & $7 / 49(14)$ & $14 / 137(10)$ & $4 / 25(16)$ & $25 / 211(12)$ \\
\hline Infusion-related reaction & $13 / 49(27)$ & $10 / 137(7)$ & $2 / 25(8)$ & $25 / 211(12)$ \\
\hline
\end{tabular}

Table 2: Safety and exposure of patisiran during the Global OLE 
$\mathrm{AE}=$ adverse event. $\mathrm{OLE}=$ open-label extension. $\mathrm{SD}=$ standard deviation. ${ }^{*}$ All deaths summarised, including deaths due to $\mathrm{AEs}$ that are not treatment emergent. ${ }^{\dagger}$ In this group, 1 additional patient with breast cancer died 6.5 months after withdrawing from the study. 


\begin{tabular}{|c|c|c|c|c|}
\hline $\begin{array}{l}\text { Number of patients } \\
(\%)^{*} / \text { number of eventst }\end{array}$ & $\begin{array}{l}\text { APOLLO- } \\
\text { placebo } \\
(n=49)\end{array}$ & $\begin{array}{l}\text { APOLLO- } \\
\text { patisiran } \\
(n=137)\end{array}$ & $\begin{array}{l}\text { Phase } 2 \text { OLE } \\
\text { patisiran } \\
(n=25)\end{array}$ & $\begin{array}{l}\text { Global OLE total } \\
(\mathrm{n}=\mathbf{2 1 1})\end{array}$ \\
\hline At least $1 \mathrm{SAE}$ & $28 / 49(57) / 76$ & $48 / 137(35) / 88$ & $6 / 25(24) / 8$ & $82 / 211(39) / 172$ \\
\hline Cerebrovascular accident & $1 / 49(2) / 1$ & $3 / 137(2) / 3$ & $1 / 25(4) / 1$ & $5 / 211(2) / 5$ \\
\hline Cardiac arrest & $4 / 49(8) / 5$ & $0 / 137(0)$ & $0 / 25(0)$ & $4 / 211(2) / 5$ \\
\hline Syncope & $2 / 49(4) / 2$ & $2 / 137(1) / 2$ & $0 / 25(0)$ & $4 / 211(2) / 4$ \\
\hline Acute myocardial infarction & $1 / 49(2) / 1$ & $2 / 137(1) / 2$ & $0 / 25(0)$ & $3 / 211(1) / 3$ \\
\hline Asthenia & $1 / 49(2) / 1$ & $2 / 137(1) / 2$ & $0 / 25(0)$ & $3 / 211(1) / 3$ \\
\hline Cardiac failure & $1 / 49(2) / 1$ & $1 / 137(1) / 3$ & $1 / 25(4) / 1$ & $3 / 211(1) / 5$ \\
\hline Cardiac failure congestive & $1 / 49(2) / 1$ & $2 / 137(1) / 2$ & $0 / 25(0)$ & $3 / 211(1) / 3$ \\
\hline Cellulitis & $1 / 49(2) / 2$ & $2 / 137(1) / 2$ & $0 / 25(0)$ & $3 / 211(1) / 4$ \\
\hline Conduction disorder & $0 / 49(0)$ & $3 / 137(2) / 3$ & $0 / 25(0)$ & $3 / 211(1) / 3$ \\
\hline Hip fracture & $2 / 49(4) / 2$ & $1 / 137(1) / 1$ & $0 / 25(0)$ & $3 / 211(1) / 3$ \\
\hline Pneumonia & $2 / 49(4) / 2$ & $1 / 137(1) / 1$ & $0 / 25(0)$ & $3 / 211(1) / 3$ \\
\hline Urinary tract infection & $3 / 49(6) / 3$ & $0 / 137(0)$ & $0 / 25(0)$ & $3 / 211(1) / 3$ \\
\hline
\end{tabular}

$\mathrm{OLE}=$ open-label extension. $\mathrm{SAE}=$ serious adverse event. ${ }^{*}$ If a patient experienced more than 1 event with a given preferred term, that patient is counted only once for that preferred term. The total number of events for all patients; a patient can be counted more than once if the patient has multiple events. 


\section{Appendix}

\section{Table of Contents}

Methods 2

$\begin{array}{ll}\text { Procedures } & 2\end{array}$

Outcomes 2

Statistical analysis $\quad 2$

Appendix Table 1: Global OLE study sites $\quad 3$

Appendix Table 2: Global OLE outcome measure ranges 4

Appendix Table 3: All Global OLE outcome measures 5

Appendix Table 4: Description of patient deaths during the Global OLE 6

Appendix Table 5: Change from parent study baseline and Global OLE enrolment

to Global OLE 12 months in PND and FAP $\quad 7$

Appendix Table 6: Change in select clinical assessments from parent study baseline and Global OLE enrolment to Global OLE 12 months $\quad 8$

Appendix Table 7: Summary of IRR events in the Global OLE 9

Appendix Table 8: Integrated exposure-adjusted mortality rates across the patisiran development programme in $\begin{array}{ll}\text { patients with ATTRv amyloidosis with polyneuropathy } & 10\end{array}$

Appendix Table 9: Patisiran Global OLE study group by study site 11

Appendix Figure 1: Serum TTR levels (mg/L) up to Global OLE 12 months 19

Appendix Figure 2: Post hoc analysis of exposure-adjusted mortality rates by genotype and baseline NT-proBNP

$\begin{array}{ll}\text { levels in APOLLO } & 20\end{array}$ 


\section{Methods}

The current study protocol is available from:

https://www.alnylam.com/OLE-Study-Protocol-Amendment.pdf

The APOLLO study protocol is available from:

https://www.nejm.org/doi/suppl/10.1056/NEJMoa1716153/suppl_file/nejmoa1716153_protocol.pdf

\section{Procedures}

All patients received premedication comprising $10 \mathrm{mg}$ of dexamethasone intravenously (IV) or equivalent corticosteroid, acetaminophen/paracetamol orally, and $\mathrm{H} 1 / \mathrm{H} 2$ blockers IV.

\section{Outcomes}

Deaths were adjudicated as cardiovascular (CV), non-cardiovascular (non-CV), or unknown.

\section{Statistical analysis}

Patisiran exposure was calculated as cumulative exposure across the trials based on the patient's first and most recent dose. Descriptive statistics for clinical laboratory tests, vital signs, and efficacy parameters were presented as actual values and changes from baseline (calculated within patient). The integrated exposure-adjusted mortality rate was conducted post hoc and calculated as total number of deaths per total patient-years (PY) of exposure $\times 100$; deaths occurring between first patisiran dose and 90 days after the last dose were included in the calculation. The total patient-year exposure time was calculated as the sum of each patient's time using a minimum of the exposure time in years or follow-up time in years (applying a data cut-off of 24 September 2018). A post hoc analysis of exposure-adjusted mortality between the treatment groups in APOLLO was performed by evaluating mortality in subgroups of patients with the non-V30M genotype and/or elevated serum NT-proBNP at APOLLO baseline (>3000 pg/mL; indicative of cardiac involvement). 


\section{Appendix Table 1: Global OLE study sites*}

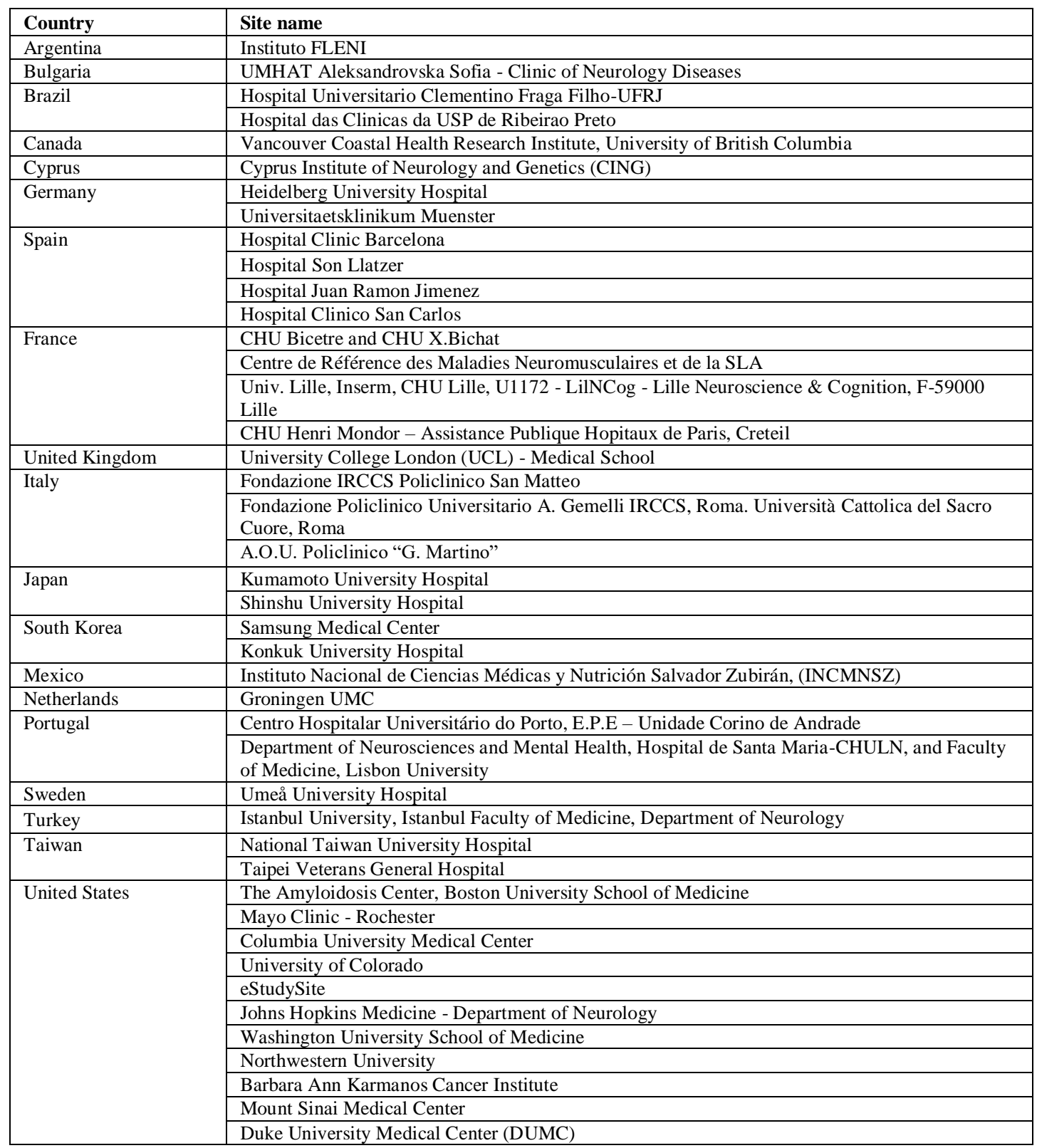

*Sites listed include those that enrolled patients as of 24 September 2018. 


\section{Appendix Table 2: Global OLE outcome measure ranges}

\begin{tabular}{|l|l|}
\hline Outcome measure & Range of scoring system \\
\hline Neurologic impairment assessed using NIS & $0-244:$ maximum impairment, 244 \\
\hline Motor function assessed by NIS-W & $0-192:$ maximum impairment, 192 \\
\hline Neurologic impairment assessed using mNIS +7 & $0-304:$ maximum impairment, 304 \\
\hline Neurologic impairment assessed using NIS+7 & $0-270:$ maximum impairment, 270 \\
\hline Quality of life using Norfolk QOL-DN & -4 to 136: lowest QOL, 136 \\
\hline Autonomic function assessed using COMPASS-31 & $0-100:$ maximum impairment, 100 \\
\hline Disability reported by patients using R-ODS & $0-48:$ highest disability, 0 \\
\hline Ambulation assessed by PND score & $0-$ IV: maximum impairment, IV \\
\hline Ambulation assessed by FAP stage & $0-3$ : maximum impairment, 3 \\
\hline
\end{tabular}

COMPASS-31=Composite Autonomic Symptom Score-31. EQ-5D=EuroQOL questionnaire. FAP=familial amyloid polyneuropathy. mNIS+7=modified Neuropathy Impairment Score+7. NIS=Neuropathy Impairment Score. NIS+7=Neuropathy Impairment Score+7. NIS W=NIS-Weakness. Norfolk QOL-DN=Norfolk Quality of Life-Diabetic Neuropathy questionnaire. OLE=open-label extension. PND=polyneuropathy disability. R-ODS=Rasch-built Overall Disability Scale. 


\section{Appendix Table 3: All Global OLE outcome measures}

\begin{tabular}{|l|}
\hline Outcome measure \\
\hline Neurologic impairment assessed using NIS \\
\hline Neurologic impairment assessed using mNIS +7 \\
\hline Neurologic impairment assessed using NIS+7 \\
\hline Quality of life using Norfolk QOL-DN \\
\hline Quality of life using EQ-5D \\
\hline Autonomic function assessed using COMPASS-31 \\
\hline Serum TTR lowering \\
\hline Nutritional status using mBMI \\
\hline Disability reported by patients using R-ODS \\
\hline Motor function assessed by NIS-W \\
\hline Motor function assessed by timed 10-MWT \\
\hline Motor function assessed by grip strength test \\
\hline Ambulation assessed by PND score \\
\hline Ambulation assessed by FAP stage \\
\hline Nerve fibre density assessed by IENFD and SGNFD \\
\hline Serum vitamin A \\
\hline Serum NT-proBNP \\
\hline Serum troponin I \\
\hline Magnetic resonance neurography (Germany and France only) \\
\hline Cardiac structure and function assessed by echocardiograms \\
\hline Burden of disease and healthcare utilisation using a patient-reported pharmacoeconomics questionnaire \\
\hline
\end{tabular}

10-MWT=10-metre walk test. COMPASS-31=Composite Autonomic Symptom Score-31. EQ-5D=EuroQOL questionnaire. FAP=familial amyloid polyneuropathy. IENFD=intraepidermal nerve fibre density. $\mathrm{mBMI}=$ modified body mass index. $\mathrm{mNIS}+7=\mathrm{modified} \mathrm{Neuropathy}$ Impairment Score+7. NIS=Neuropathy Impairment Score. NIS+7= Neuropathy Impairment Score+7. NIS-W=NIS-Weakness. Norfolk QOLDN=Norfolk Quality of Life-Diabetic Neuropathy questionnaire. NT-proBNP=N-terminal prohormone of B-type natriuretic peptide. OLE=openlabel extension. PND=polyneuropathy disability. R-ODS=Rasch-built Overall Disability Scale. SGNFD=sweat gland nerve fibre density. TTR=transthyretin. 
Appendix Table 4: Description of patient deaths during the Global OLE*

\begin{tabular}{|c|c|c|c|c|c|c|}
\hline Treatment arm & $\begin{array}{c}\text { Age }^{\dagger /} \\
\text { Gender }\end{array}$ & Genotype & $\begin{array}{c}\text { NT-proBNP at } \\
\text { Global OLE } \\
\text { enrolment } \\
(\mathrm{pg} / \mathrm{mL})\end{array}$ & $\begin{array}{c}\text { PND at } \\
\text { Global OLE } \\
\text { enrolment }\end{array}$ & AEs leading to death & $\begin{array}{c}\text { Relationship to } \\
\text { study drug }\end{array}$ \\
\hline APOLLO-placebo & $38 / \mathrm{M}$ & V30M & 106 & IIIB & Hip fracture & Unrelated \\
\hline APOLLO-placebo & $59 / \mathrm{M}$ & F64L & 6905 & II & Arrhythmia & Unrelated \\
\hline APOLLO-placebo & $60 / \mathrm{M}$ & E89Q & 3784 & II & Dehydration & Unrelated \\
\hline APOLLO-placebo & $74 / \mathrm{M}$ & V30M & 15101 & IV & Pancreatitis & Unrelated \\
\hline APOLLO-placebo & $66 / \mathrm{M}$ & S77Y & 3160 & II & Hypovolaemic shock & Unrelated \\
\hline APOLLO-placebo & $72 / \mathrm{M}$ & V30M & 3052 & IV & Cardiac arrest & Unrelated \\
\hline APOLLO-placebo & $66 / \mathrm{M}$ & T60A & 868 & IIIB & Amyloidosis & Unrelated \\
\hline APOLLO-placebo & $74 / \mathrm{M}$ & V30M & 2169 & IIIB & Cardiac arrest & Unrelated \\
\hline APOLLO-placebo & $69 / \mathrm{F}$ & I84T & 1333 & II & $\begin{array}{c}\text { Acute respiratory distress } \\
\text { syndrome, haemorrhagic shock }\end{array}$ & Unrelated \\
\hline APOLLO-placebo & $53 / \mathrm{F}$ & S50R & 436 & IIIB & Septic shock & Unrelated \\
\hline APOLLO-placebo & $77 / \mathrm{M}$ & A97S & 2501 & IIIB & Acute myocardial infarction & Unrelated \\
\hline APOLLO-placebo & $74 / \mathrm{F}$ & A97S & 1790 & IV & Cardiogenic shock & Unrelated \\
\hline APOLLO-placebo & $68 / \mathrm{M}$ & E89Q & 1583 & IV & Cardiac arrest & Unrelated \\
\hline APOLLO-patisiran & $81 / \mathrm{M}$ & V30M & 3218 & IIIA & Cerebrovascular accident & Unrelated \\
\hline APOLLO-patisiran & $77 / \mathrm{F}$ & T60A & 1542 & IIIB & Death (cause unknown) & Unrelated \\
\hline APOLLO-patisiran & 76/M & V30M & 1144 & IIIA & $\begin{array}{c}\text { Acute myocardial infarction, } \\
\text { Atrial flutter, Acute kidney injury }\end{array}$ & Unrelated \\
\hline APOLLO-patisiran & $72 / \mathrm{M}$ & T60A & 10282 & II & Chronic kidney disease & Unrelated \\
\hline APOLLO-patisiran & $70 / \mathrm{M}$ & T60A & 3844 & IV & Familial amyloidosis & Unrelated \\
\hline APOLLO-patisiran & $70 / \mathrm{M}$ & L58H & 376 & II & Acute myocardial infarction & Unrelated \\
\hline APOLLO-patisiran & $66 / \mathrm{M}$ & T60A & 6145 & IV & Amyloidosis & Unrelated \\
\hline APOLLO-patisiran & $52 / \mathrm{M}$ & S50R & 2811 & IIIA & Neurogenic shock & Unrelated \\
\hline APOLLO-patisiran & $41 / \mathrm{M}$ & S50R & 4932 & IV & $\begin{array}{l}\text { Electrolyte imbalance, Acute } \\
\text { respiratory failure }\end{array}$ & Unrelated \\
\hline APOLLO-patisiran & $70 / \mathrm{F}$ & A97S & 2218 & IIIB & Cardiopulmonary failure & Unrelated \\
\hline
\end{tabular}

$\mathrm{AE}=$ adverse event. $\mathrm{F}=$ female. $\mathrm{M}=$ male. NT-proBNP=N-terminal prohormone of B-type natriuretic peptide. OLE=open-label extension. PND=polyneuropathy disability. "Includes deaths occurring within 90 days of last dose of patisiran. ${ }^{\dagger}$ Patient age at death. Investigators could report $>1$ adverse event as leading to death for a patient. 
Appendix Table 5: Change from parent study baseline and Global OLE enrolment to Global OLE 12 months in PND and FAP

\begin{tabular}{|c|c|c|c|c|c|c|}
\hline \multirow[t]{2}{*}{ Assessment, n (\%) } & \multicolumn{3}{|c|}{ From parent study baseline } & \multicolumn{3}{|c|}{$\begin{array}{c}\text { From Global OLE enrolment } \\
\end{array}$} \\
\hline & $\begin{array}{c}\text { APOLLO- } \\
\text { placebo } \\
(n=77)\end{array}$ & $\begin{array}{c}\text { APOLLO- } \\
\text { patisiran } \\
(n=148)\end{array}$ & $\begin{array}{c}\text { Phase } 2 \text { OLE } \\
\text { patisiran } \\
(n=27)\end{array}$ & $\begin{array}{c}\text { APOLLO- } \\
\text { placebo } \\
(n=49)\end{array}$ & $\begin{array}{c}\text { APOLLO- } \\
\text { patisiran } \\
(n=137)\end{array}$ & $\begin{array}{c}\text { Phase } 2 \text { OLE } \\
\text { patisiran } \\
(n=25)\end{array}$ \\
\hline $\begin{array}{l}\text { PND score } \\
\text { Improved } \\
\text { No change } \\
\text { Worsened } \\
\text { Missing } \\
\end{array}$ & $\begin{array}{l}0 / 77(0 \cdot 0) \\
17 / 77(22) \\
21 / 77(27) \\
39 / 77(51) \\
\end{array}$ & $\begin{array}{c}12 / 148(8) \\
77 / 148(52) \\
37 / 148(25) \\
22 / 148(15) \\
\end{array}$ & $\begin{array}{c}1 / 27(4) \\
16 / 27(59) \\
8 / 27(30) \\
2 / 27(7) \\
\end{array}$ & $\begin{array}{c}6 / 49(12) \\
27 / 49(55) \\
5 / 49(10) \\
11 / 49(22) \\
\end{array}$ & $\begin{array}{c}9 / 137(7) \\
97 / 137(71) \\
20 / 137(15) \\
11 / 137(8) \\
\end{array}$ & $\begin{array}{c}1 / 25(4) \\
20 / 25(80) \\
4 / 25(16) \\
0 / 25(0) \\
\end{array}$ \\
\hline $\begin{array}{l}\text { FAP stage } \\
\text { Improved } \\
\text { No change } \\
\text { Worsened } \\
\text { Missing }\end{array}$ & $\begin{array}{c}1 / 77(1) \\
22 / 77(29) \\
15 / 77(19) \\
39 / 77(51)\end{array}$ & $\begin{array}{c}6 / 148(4) \\
100 / 148(68) \\
20 / 148(14) \\
22 / 148(15)\end{array}$ & $\begin{array}{c}0 / 27(0) \\
21 / 27(78) \\
4 / 27(15) \\
2 / 27(7)\end{array}$ & $\begin{array}{c}2 / 49(4) \\
32 / 49(65) \\
4 / 49(8) \\
11 / 49(22)\end{array}$ & $\begin{array}{c}4 / 137(3) \\
115 / 137(84) \\
7 / 137(5) \\
11 / 137(8)\end{array}$ & $\begin{array}{c}0 / 25(0) \\
24 / 25(96) \\
1 / 25(4) \\
0 / 25(0)\end{array}$ \\
\hline
\end{tabular}

$\mathrm{FAP}=$ familial amyloid polyneuropathy. OLE=open-label extension. $\mathrm{PND}=$ polyneuropathy disability. 
Appendix Table 6: Change in select clinical assessments from parent study baseline and Global OLE enrolment to Global OLE 12 months

\begin{tabular}{|c|c|c|c|}
\hline Mean (SD) & $\begin{array}{c}\text { APOLLO- } \\
\text { placebo } \\
(\mathrm{n}=49)^{*}\end{array}$ & $\begin{array}{c}\text { APOLLO- } \\
\text { patisiran } \\
(\mathrm{n}=137)^{*}\end{array}$ & $\begin{array}{c}\text { Phase 2 OLE } \\
\text { patisiran } \\
(\mathbf{n}=25)^{*} \\
\end{array}$ \\
\hline $\begin{array}{l}\text { 10-MWT, } \mathrm{ms}^{-1} \\
\text { Parent study baseline } \\
\text { Global OLE enrolment } \\
\text { Global OLE } 12 \text { months }{ }^{\dagger} \\
\text { Change from parent study baseline } \\
\text { Change from Global OLE enrolment }\end{array}$ & $\begin{array}{c}0.79(0.32) \\
0.54(0.39) \\
0.60(0.42) \\
-0.21(0.35) \\
0.05(0.22)\end{array}$ & $\begin{array}{c}0.80(0.40) \\
0.85(0.49) \\
0.90(0.48) \\
0.06(0.26) \\
-0.01(0.20)\end{array}$ & $\begin{array}{c}1 \cdot 14(0 \cdot 43) \\
1 \cdot 26(0 \cdot 41) \\
1 \cdot 21(0 \cdot 42) \\
0 \cdot 04(0 \cdot 26) \\
-0 \cdot 06(0 \cdot 19)\end{array}$ \\
\hline $\begin{array}{l}\text { Grip strength, kg } \\
\text { Parent study baseline } \\
\text { Global OLE enrolment } \\
\text { Global OLE } 12 \text { months }{ }^{\dagger} \\
\text { Change from parent study baseline } \\
\text { Change from Global OLE enrolment }\end{array}$ & $\begin{array}{c}17 \cdot 80(10 \cdot 67) \\
10 \cdot 23(9 \cdot 05) \\
11.01(9 \cdot 43) \\
-8 \cdot 76(7.42) \\
0 \cdot 14(2 \cdot 84)\end{array}$ & $\begin{array}{c}18.40(13.57) \\
18.03(12.65) \\
18.69(14.20) \\
-0.89(9.19) \\
-0.25(6.81)\end{array}$ & $\begin{array}{c}25 \cdot 81(11 \cdot 86) \\
27 \cdot 86(13 \cdot 13) \\
27 \cdot 57(13 \cdot 41) \\
2 \cdot 03(5 \cdot 83) \\
-0 \cdot 28(4 \cdot 04) \\
\end{array}$ \\
\hline $\begin{array}{l}\text { NT-proBNP }{ }^{\ddagger}, \mathrm{pg} / \mathrm{mL} \\
\text { Parent study baseline } \\
\text { Global OLE enrolment } \\
\text { Global OLE } 12 \text { months } \\
\text { Fold change relative to Global OLE enrolment } \\
\text { (geometric mean fold change, } 95 \% \mathrm{CI} \text { ) } \\
\text { Fold change relative to parent baseline (geometric } \\
\text { mean fold change, } 95 \% \mathrm{CI} \text { ) }\end{array}$ & $\begin{array}{l}531 \cdot 29(86 \cdot 66) \\
837 \cdot 39(171 \cdot 19) \\
654 \cdot 32(149 \cdot 75) \\
1 \cdot 07(0 \cdot 86-1 \cdot 32) \\
2 \cdot 01(1 \cdot 61-2 \cdot 52)\end{array}$ & $\begin{array}{l}531 \cdot 04(59 \cdot 62) \\
396 \cdot 84(47 \cdot 77) \\
405 \cdot 44(51 \cdot 41)\end{array}$ & $\begin{array}{c}508 \cdot 13(185 \cdot 23) \\
113 \cdot 35(33 \cdot 92) \\
120 \cdot 47(39 \cdot 58)\end{array}$ \\
\hline
\end{tabular}

10-MWT $=10$-metre walk test. $\mathrm{CI}=$ confidence interval. NT-proBNP=N-terminal prohormone of B-type natriuretic peptide. $\mathrm{OLE}=\mathrm{open}$-label extension. $\mathrm{SD}=$ standard deviation. ${ }^{*}$ Patients in parent study: APOLLO-placebo, $\mathrm{n}=77$; APOLLO-patisiran, $\mathrm{n}=148$; phase 2 OLE, $\mathrm{n}=27$. ${ }^{\dagger} \mathrm{n}=38,124$ and 25 for patients in APOLLO-placebo, APOLLO-patisiran, and phase 2 OLE, respectively. ${ }^{\ddagger}$ Geometric mean NT-proBNP $(\mathrm{pg} / \mathrm{mL})$ and standard error of the mean. ${ }^{\S} \mathrm{n}=38,119$, and 25 for patients in APOLLO-placebo, APOLLO-patisiran, and phase 2 OLE, respectively. 
Appendix Table 7: Summary of IRR events in the Global OLE

\begin{tabular}{|c|c|c|c|c|}
\hline Number of patients $(\%) * /$ number of events ${ }^{\dagger}$ & $\begin{array}{c}\text { APOLLO- } \\
\text { placebo } \\
(n=49)\end{array}$ & $\begin{array}{c}\text { APOLLO- } \\
\text { patisiran } \\
(n=137)\end{array}$ & $\begin{array}{l}\text { Phase } 2 \text { OLE } \\
\text { patisiran } \\
(n=25)\end{array}$ & $\begin{array}{c}\text { Global OLE } \\
\text { total } \\
(n=211)\end{array}$ \\
\hline Number of patients with at least 1 IRR & $13 / 49(27)$ & $10 / 137(7)$ & $2 / 25(8)$ & $25 / 211(12)$ \\
\hline Total number of IRRs & 77 & 81 & 16 & 174 \\
\hline \multicolumn{5}{|l|}{ Number of patients with IRR symptoms and number of symptoms } \\
\hline Nausea & $1 / 49(2) / 2$ & $1 / 137(1) / 1$ & $0 / 25(0)$ & $2 / 211(1) / 3$ \\
\hline Injection site swelling & $2 / 49(4) / 2$ & $0 / 137(0)$ & $0 / 25(0)$ & $2 / 211(1) / 2$ \\
\hline Back pain & $2 / 49(4) / 25$ & $2 / 137(1) / 26$ & $1 / 25(4) / 1$ & $5 / 211(2) / 52$ \\
\hline Neck pain & $2 / 49(4) / 2$ & $0 / 137(0)$ & $0 / 25(0)$ & $2 / 211(1) / 2$ \\
\hline Dizziness & $0 / 49(0)$ & $1 / 137(1) / 1$ & $1 / 25(4) / 15$ & $2 / 211(1) / 16$ \\
\hline Headache & $0 / 49(0)$ & $1 / 137(1) / 4$ & $1 / 25(4) / 1$ & $2 / 211(1) / 5$ \\
\hline Apathy & $1 / 49(2) / 1$ & $1 / 137(1) / 1$ & $0 / 25(0)$ & $2 / 211(1) / 2$ \\
\hline Erythema & $1 / 49(2) / 1$ & $1 / 137(1) / 1$ & $0 / 25(0)$ & $2 / 211(1) / 2$ \\
\hline Pruritus & $0 / 49(0)$ & $2 / 137(1) / 2$ & $0 / 25(0)$ & $2 / 211(1) / 2$ \\
\hline Rash & $2 / 49(4) / 3$ & $1 / 137(1) / 1$ & $0 / 25(0)$ & $3 / 211(1) / 4$ \\
\hline Flushing & $2 / 49(4) / 18$ & $2 / 137(1) / 41$ & $1 / 25(4) / 1$ & $5 / 211(2) / 60$ \\
\hline Hypertension & $2 / 49(4) / 2$ & $1 / 137(1) / 1$ & $0 / 25(0)$ & $3 / 211(1) / 3$ \\
\hline $\begin{array}{l}\text { Number of patients with IRR leading to infusion, interruption } \\
\text { and number of interruptions }\end{array}$ & $4 / 49(8) / 7$ & $0 / 137(0)$ & $1 / 25(4) / 1$ & $5 / 211(2) / 8$ \\
\hline Number of patients with IRR leading to treatment discontinuation & $0 / 49(0)$ & $0 / 137(0)$ & $0 / 25(0)$ & $0 / 211(0)$ \\
\hline
\end{tabular}

IRR=infusion-related reaction. OLE=open-label extension. *If a patient experienced more than 1 event with a given preferred term, that patient is counted only once for that preferred term. The total number of events for all patients; a patient can be counted more than once if the patient has multiple events. 
Appendix Table 8: Integrated exposure-adjusted mortality rates across the patisiran development programme in patients with ATTRv amyloidosis with polyneuropathy

\begin{tabular}{|c|c|c|c|c|}
\hline & $\begin{array}{l}\text { APOLLO- } \\
\text { placebo } \\
(n=49)\end{array}$ & $\begin{array}{l}\text { APOLLO- } \\
\text { patisiran } \\
(n=148)\end{array}$ & $\begin{array}{c}\text { Phase } 2 \text { OLE } \\
\text { patisiran } \\
(n=27)\end{array}$ & $\begin{array}{l}\text { All patisiran- } \\
\text { treated patients* } \\
\quad(n=224)\end{array}$ \\
\hline Total patient-years exposure & $68 \cdot 6$ & $442 \cdot 2$ & $118 \cdot 6$ & $629 \cdot 4$ \\
\hline Deaths $^{\dagger}, \mathbf{n}(\%)$ & $13 / 49(27)$ & $15 / 148(10)$ & $2 / 27(7)$ & $30 / 224(13)$ \\
\hline $\begin{array}{l}\text { Overall exposure-adjusted mortality rate, } \\
\text { deaths per } 100 \text { patient-years }(95 \% \mathrm{CI})\end{array}$ & $\begin{array}{c}18 \cdot 9 \\
(10 \cdot 4-31 \cdot 2)\end{array}$ & $\begin{array}{c}3 \cdot 4 \\
(2 \cdot 0-5 \cdot 4)\end{array}$ & $\begin{array}{c}1 \cdot 7 \\
(0 \cdot 3-5 \cdot 2)\end{array}$ & $\begin{array}{c}4 \cdot 8 \\
(3 \cdot 3-6 \cdot 7)\end{array}$ \\
\hline Cardiac deaths, ${ }^{\dagger, *} \mathbf{n}(\%)$ & $6 / 49(12)$ & $11 / 148(7)$ & $1 / 27(4)$ & $18 / 224(8)$ \\
\hline $\begin{array}{l}\text { Exposure-adjusted cardiac mortality rate, } \\
\text { deaths per } 100 \text { patient-years }(95 \% \mathrm{CI})\end{array}$ & $8 \cdot 7(3 \cdot 5-17 \cdot 7)$ & $2 \cdot 5(1 \cdot 3-4 \cdot 3)$ & $0 \cdot 8(0 \cdot 05-3 \cdot 7)$ & $2 \cdot 9(1.7-4 \cdot 4)$ \\
\hline
\end{tabular}

ATTRv=hereditary transthyretin; $\mathrm{CI}=$ confidence interval. OLE=open-label extension. *The integrated safety population encompasses all patients exposed to patisiran. Data are recorded from first patisiran dose in either the APOLLO, Phase 2 OLE, or Global OLE studies until Global OLE 12 months. Includes all deaths reported within 3 months after the last dose of patisiran. ${ }^{\ddagger}$ Cardiac deaths were considered a subset of deaths adjudicated as being cardiovascular-related, excluding the subcategory of fatal stroke. Post hoc analysis of exposureadjusted mortality rate is calculated as: (total number of deaths/total patient-years of exposure) $\times 100$. For each patient, exposure in years is defined as: (last dose date of study drug - first dose date of study drug+91)/365 25 . The total patient-years of exposure time is calculated as the sum of each patient's time using the minimum of the exposure time in years or the follow-up time in years (applying the 24 September 2018 cut-off to data from the Global OLE study). 


\section{Appendix Table 9: Patisiran Global OLE study group by study site}

\begin{tabular}{|c|c|c|}
\hline Study site & Role & Name \\
\hline \multirow{5}{*}{ A.O.U. Policlinico “G. Martino”, Italy } & Primary Investigator & Giuseppe Vita \\
\hline & \multirow{4}{*}{ Investigators } & Vincenzo Rizzo \\
\hline & & Massimo Russo \\
\hline & & Anna Mazzeo \\
\hline & & Luca Gentile \\
\hline \multirow{4}{*}{$\begin{array}{l}\text { The Amyloidosis Center, Boston University School of Medicine, United } \\
\text { States }\end{array}$} & Primary Investigator & John L Berk \\
\hline & \multirow{2}{*}{ Study Coordinators } & Caitlin Brueckner \\
\hline & & Victoria Lazzari \\
\hline & Investigator & Janice Wiesman \\
\hline \multirow{5}{*}{ Bassett Medical Center, United States } & Primary Investigator & Douglas DeLong \\
\hline & Study Coordinator & Jennifer Victory \\
\hline & \multirow{2}{*}{ Investigators } & James Dalton \\
\hline & & John May \\
\hline & Clinical research nurse & Catherine Gilmore \\
\hline \multirow{7}{*}{$\begin{array}{l}\text { Centre de Référence des Maladies Neuromusculaires et de la SLA, } \\
\text { France }\end{array}$} & Primary Investigator & Shahram Attarian \\
\hline & Study Coordinator & Saran Diallo \\
\hline & \multirow{5}{*}{ Investigators } & Emilien Delmont \\
\hline & & Jean Pouget \\
\hline & & Annie Verschueren \\
\hline & & Aude-Marie Grapperon \\
\hline & & Emmanuelle Campana-Salort \\
\hline \multirow{11}{*}{$\begin{array}{l}\text { Department of Neurosciences and Mental Health, Hospital de Santa } \\
\text { Maria-CHULN, and Faculty of Medicine, Lisbon University, Portugal }\end{array}$} & Primary Investigator & Isabel M Conceição \\
\hline & \multirow{2}{*}{ Study Coordinator } & Ana Lopes \\
\hline & & Filipa Lamas \\
\hline & \multirow{8}{*}{ Investigators } & Carlos Neves \\
\hline & & Jose Castro \\
\hline & & Pedro Pereira \\
\hline & & Isabel Castro \\
\hline & & Ana Franco \\
\hline & & Miguel Oliveira Santos \\
\hline & & Conceição de Azevedo Coutinho \\
\hline & & Catarina Falcao de Campos \\
\hline \multirow{14}{*}{$\begin{array}{l}\text { Centro Hospitalar Universitário do Porto, E.P.E - Unidade Corino de } \\
\text { Andrade, Portugal }\end{array}$} & Primary Investigator & Teresa Coelho \\
\hline & \multirow{13}{*}{ Investigators } & Antonio Hipólito Reis \\
\hline & & Nuno Correia \\
\hline & & Javier M Perez \\
\hline & & Ana Martins da Silva \\
\hline & & Cristina Alves \\
\hline & & Marcio Cardoso \\
\hline & & Katia Valdrez \\
\hline & & Julia R Monte \\
\hline & & Bernardete Pessoa \\
\hline & & Nadia Guimaraes \\
\hline & & Monica Freitas \\
\hline & & Joana Ramalho \\
\hline & & Natalia Ferreira \\
\hline Chikamori Hospital, Japan & Primary Investigator & Daisuke Kuzume \\
\hline \multirow{9}{*}{$\begin{array}{l}\text { Univ. Lille, Inserm, CHU Lille, U1172 - LilNCog - Lille Neuroscience \& } \\
\text { Cognition, F-59000 Lille, France }\end{array}$} & Primary Investigator & Celine Tard \\
\hline & \multirow{6}{*}{ Study Coordinators } & Nawal Waucquier \\
\hline & & Isabelle Rougeaux \\
\hline & & Sylvie Brice \\
\hline & & Emmanuelle Kasprzyk \\
\hline & & Elise Elrezzi \\
\hline & & Sayah Meguig \\
\hline & \multirow{2}{*}{ Investigators } & Eric Hachulla \\
\hline & & Clement Gauvain \\
\hline
\end{tabular}




\begin{tabular}{|c|c|c|}
\hline & & Maria-Claire Migaud-Chervy \\
\hline & & Dominique Deplanque \\
\hline & & Elsa Jozefowicz \\
\hline & & Loic Lebellec \\
\hline \multirow{23}{*}{ CHU Bicetre and CHU X.Bichat, France } & Primary Investigator & David Adams \\
\hline & \multirow{9}{*}{ Study Coordinators } & Line Balaya-Gouraya \\
\hline & & Nathalie Jehan Lacour \\
\hline & & Halima Bournane \\
\hline & & Nathalie Martin \\
\hline & & Mongia Elabed \\
\hline & & Niamey Sacko \\
\hline & & Yasmine Boubrit \\
\hline & & Amina Gaouar \\
\hline & & Fetra Rakotondratafika \\
\hline & \multirow{13}{*}{ Investigators } & Marie Théaudin-Saliou \\
\hline & & Cécile Cauquil-Michon \\
\hline & & Celine Labeyrie \\
\hline & & Adeline Not \\
\hline & & Abdallah Al-Salameh \\
\hline & & Anne-Lise Lecoq \\
\hline & & Maeva Stephant \\
\hline & & Andoni Echaniz-Laguna \\
\hline & & Laurent Becquemont \\
\hline & & Guillemette Beaudonnet \\
\hline & & Vincent Algalarrondo \\
\hline & & Ludivine Eliahou \\
\hline & & Michel S Slama \\
\hline \multirow{3}{*}{ CHU de Fort de France, Martinique (France) } & Primary Investigator & Aissatou Signate \\
\hline & \multirow{2}{*}{ Investigators } & Emeline Berthelot \\
\hline & & Jocelyn Inamo \\
\hline \multirow{9}{*}{$\begin{array}{l}\text { CHU Henri Mondor - Assistance Publique Hopitaux de Paris, Creteil, } \\
\text { France }\end{array}$} & Primary Investigator & Violaine Planté-Bordeneuve \\
\hline & \multirow{2}{*}{ Study Coordinators } & Laetitia Vervoitte \\
\hline & & Cecile Focseneanu \\
\hline & \multirow{6}{*}{ Investigators } & Thierry Gendre \\
\hline & & Raphaele Arrouasse \\
\hline & & Samar S. Ayache \\
\hline & & Laura Ernande \\
\hline & & Philippe Le Corvoisier \\
\hline & & Hayet Salhi \\
\hline \multirow{5}{*}{ CHU La Reunion, France } & Primary Investigator & Ariane Choumert \\
\hline & \multirow{2}{*}{ Study Coordinator } & Vincent Ehinger \\
\hline & & Julie Ruiz \\
\hline & \multirow{2}{*}{ Investigators } & Cyril Charlin \\
\hline & & Thomas Megelin \\
\hline \multirow{12}{*}{ Columbia University Medical Center, United States } & Primary Investigator & Thomas H Brannagan III \\
\hline & \multirow{4}{*}{ Study Coordinators } & Raisy Fayerman \\
\hline & & Arreum Kim \\
\hline & & Allan Paras \\
\hline & & Leidy J Gonzalez \\
\hline & \multirow{7}{*}{ Investigators } & Steven Tsang \\
\hline & & Fernanda Wajnsztajn \\
\hline & & Jeffrey Shije \\
\hline & & Christina Ulane \\
\hline & & Inna Kleyman \\
\hline & & Louis Weimer \\
\hline & & Comana Cioroiu \\
\hline \multirow{3}{*}{ Cyprus Institute of Neurology and Genetics (CING), Cyprus } & Primary Investigator & Sakis Lambrianides \\
\hline & Study Coordinator & Rana Abu-Manneh \\
\hline & Investigators & Eleni Zamba-Papanicolaou \\
\hline
\end{tabular}




\begin{tabular}{|c|c|c|}
\hline & & Petros Agathangelou \\
\hline & & Eleni Leonidou \\
\hline \multirow{6}{*}{ Ehime University Hospital, Japan } & Primary Investigator & Satoshi Tada \\
\hline & Study Coordinator & Akemi Fujita \\
\hline & \multirow{4}{*}{ Investigators } & Masahiro Nagai \\
\hline & & Rina Ando \\
\hline & & Yuko Hosokawa \\
\hline & & Yuki Yamanishi \\
\hline \multirow{26}{*}{ eStudySite, United States } & Primary Investigator & J Scott Overcash \\
\hline & \multirow{18}{*}{ Study Coordinators } & Elena Giardino \\
\hline & & Leslie Boyer \\
\hline & & Lien Dang \\
\hline & & An Le \\
\hline & & Tyler Nguyen \\
\hline & & Lien Giang \\
\hline & & Peter Sellers \\
\hline & & Leyla Tran \\
\hline & & Nghi Truong \\
\hline & & Maita Vinas \\
\hline & & Nicole Hrkman \\
\hline & & Sarah Miller \\
\hline & & David Nguyen \\
\hline & & Ashley Smith \\
\hline & & Helen $\mathrm{Pu}$ \\
\hline & & Steve Li \\
\hline & & Thao Vuong \\
\hline & & Holly Dioso \\
\hline & \multirow{7}{*}{ Investigators } & Sinikka Green \\
\hline & & Kia Lee \\
\hline & & Hanh Chu \\
\hline & & Michael Waters \\
\hline & & Derya J Coskun \\
\hline & & Karla A Zepeda \\
\hline & & William O’Riordan \\
\hline \multirow{5}{*}{ Fondazione IRCCS Policlinico San Matteo, Italy } & Primary Investigator & Laura Obici \\
\hline & \multirow{4}{*}{ Investigators } & Andrea Cortese \\
\hline & & Alessandro Lozza \\
\hline & & Giampaolo Merlini \\
\hline & & Vittorio Rosti \\
\hline $\begin{array}{l}\text { Università Cattolica del Sacro Cuore, Roma, Italia. Centro Clinico } \\
\text { NEMO adulti - Roma, Italia }\end{array}$ & Primary Investigator & Mario Sabatelli \\
\hline Centro Clinico NEMO adulti - Roma, Italia & \multirow{7}{*}{ Investigators } & Giulia Bisogni \\
\hline Centro Clinico NEMO adulti - Roma, Italia & & Daniela Bernardo \\
\hline $\begin{array}{l}\text { Fondazione Policlinico Universitario A. Gemelli IRCCS, Roma, Italia. } \\
\text { UOC Neurologia. Università Cattolica del Sacro Cuore, Roma, Italia }\end{array}$ & & Marco Luigetti \\
\hline Università Cattolica del Sacro Cuore, Roma, Italia & & Andrea Di Paolantonio \\
\hline Università Cattolica del Sacro Cuore, Roma, Italia & & Valeria Guglielmino \\
\hline Centro Clinico NEMO adulti - Roma, Italia & & Giulia Bisogni \\
\hline $\begin{array}{l}\text { Università Cattolica del Sacro Cuore, Roma, Italia. Centro Clinico } \\
\text { NEMO adulti - Roma, Italia }\end{array}$ & & Angela Romano \\
\hline \multirow{2}{*}{ Groningen UMC, Netherlands } & Primary Investigator & Hans Nienhuis \\
\hline & Research nurse & Janita Bulthuis-Kuiper \\
\hline \multirow{7}{*}{ Heidelberg University Hospital, Germany } & Primary Investigator & Arnt V Kristen \\
\hline & \multirow{6}{*}{ Study Coordinators } & Olga Gerk \\
\hline & & Hannah Ulbricht \\
\hline & & Lenka Taylor \\
\hline & & Eva Meyle \\
\hline & & Natalia Kleinschmidt \\
\hline & & David Meyrath \\
\hline
\end{tabular}




\begin{tabular}{|c|c|c|}
\hline & & Simone Noe-Schwenn \\
\hline & & Ulrike Meng \\
\hline & \multirow{3}{*}{ Investigators } & Ralf Bauer \\
\hline & & Fabian aus dem Siepen \\
\hline & & Selina Hein \\
\hline \multirow{8}{*}{ Hiroshima University Hospital, Japan } & \multirow{2}{*}{ Primary Investigator } & Tetsuya Takahashi \\
\hline & & Tomohiko Oshita \\
\hline & Study Coordinator & Yoko Koujin \\
\hline & & Shuichiro Neshige \\
\hline & & Tomohisa Nezu \\
\hline & Investigators & Akiko Segawa \\
\hline & & Hiroki Ueno \\
\hline & & Hiroyuki Morino \\
\hline & Primary Investigator & Josep M Campistol \\
\hline Hospital Clinic Barcelona, Spain & & Lida Maria Rodas Marin \\
\hline & Investigators & Josep Miquel Blasco Pelicano \\
\hline & Primary Investigator & Lucía Galán Dávila \\
\hline & Study Coordinator & Marta Palacios \\
\hline & & Vanesa Pytel Cordoba \\
\hline Hospital Clinico San Carlos, Spain & & Antonio Guerrero Sola \\
\hline & Investigators & Alejandro Horga \\
\hline & & Julián García Feijoo \\
\hline & & Leopoldo Perez de Isla \\
\hline & Primary Investigator & Wilson Marques Júnior \\
\hline & & Mariana Moscardini \\
\hline & & Debora Cristina Litcanov \\
\hline & Study Coordinators & Ana Flavia Viera Lima \\
\hline Hospital das Clinicas da USP de Ribeirao Preto, Brazil & & Leonardo Rodrigues \\
\hline & & Barbara Marques Coutinho \\
\hline & Inyectiogtors & Carolina Lavigne Moreira \\
\hline & Investigators & Vanessa Daccach Marques \\
\hline & Primary Investigator & Francisco Munoz Beamud \\
\hline Hospital Juan Ramon Jimenez, Spain & Study Coordinator & Álvaro Gragera Martínez \\
\hline & Investigator & Cristina Borrachero \\
\hline & Primary Investigator & Inés Asunción Losada López \\
\hline & & Eugenia Cisneros Barroso \\
\hline & Study Coordinators & Adrián Rodríguez Rodríguez \\
\hline & & Monica Sanz \\
\hline & & Elena Rigo Oliver \\
\hline & & Juan González Moreno \\
\hline Hospital Son Llatzer, Spain & & Jose M Gamez Martinez \\
\hline & Investigators & Cristina Descals \\
\hline & & Mercedes Uson \\
\hline & & Francisco Jose Vega \\
\hline & & Antoni Figuerola \\
\hline & & Carles Montala \\
\hline & Primary Investigator & Márcia Waddington-Cruz \\
\hline & & Moises Dias da Silva \\
\hline & & Renata Gervais de Santa Rosa \\
\hline Hospital Universitario Clementino Fraga Filho-UFRJ, Brazil & Investigators & Luiz Felipe Pinto \\
\hline & & Marcus Vinicius Pinto \\
\hline & & Amanda Cardoso Berensztejn \\
\hline & Primary Investigator & Fabio Barroso \\
\hline Instituto FLENI, Argentina & & Andrea Lautre \\
\hline & Investigators & Lucas G Orellana \\
\hline Instituto Nacional de Ciencias Médicas y Nutrición Salvador Zubirán, & Primary Investigator & $\begin{array}{l}\text { Maria Alejandra González-Duarte } \\
\text { Briseño }\end{array}$ \\
\hline (INCMNSZ), Mexico & Studv Coordinatore & Karla Cárdenas-Soto \\
\hline & Study Coordinators & Brenda Poled Jiménez López \\
\hline
\end{tabular}




\begin{tabular}{|c|c|c|}
\hline & & Sandra Lorena Pérez-Castañeda \\
\hline & \multirow{5}{*}{ Investigators } & Carlos Gerardo Cantú Brito \\
\hline & & David Rivera de la Parra \\
\hline & & Jose Pablo Hernandez Reyes \\
\hline & & Maria del Mar Saniger Alba \\
\hline & & Elia Criollo Mora \\
\hline \multirow{11}{*}{$\begin{array}{l}\text { Istanbul University, Istanbul Faculty of Medicine, Department of } \\
\text { Neurology, Turkey }\end{array}$} & Primary Investigator & Yesim Parman \\
\hline & Study Coordinator & Kus Jülide Rezzan \\
\hline & \multirow{9}{*}{ Investigators } & Erdi Sahin \\
\hline & & Nail G Serbest \\
\hline & & Hacer Durmus \\
\hline & & Arman Cakar \\
\hline & & Nuriye Ilknur Tugal Tutkun \\
\hline & & Sacit Karamursel \\
\hline & & Ali Elitok \\
\hline & & Nermin G Sirin Inan \\
\hline & & Emre Altinkurt \\
\hline \multirow{12}{*}{ Johns Hopkins Medicine - Department of Neurology, United States } & Primary Investigator & Michael Polydefkis \\
\hline & Study Coordinators & Jing Ye \\
\hline & \multirow{10}{*}{ Investigators } & Adriane C Allen \\
\hline & & Vinay Chaudhry \\
\hline & & Raquel Jarrett \\
\hline & & Neil Bressler \\
\hline & & Kathleen L Burks \\
\hline & & Qingfeng Liu \\
\hline & & Mohammad Khoshnoodi \\
\hline & & Daniel P Judge \\
\hline & & Geno Vista \\
\hline & & Syed Mahmood Shah \\
\hline \multirow{10}{*}{ Kita-Harima Medical Center, Japan } & Primary Investigator & Hirotoshi Hamaguchi \\
\hline & \multirow{3}{*}{ Study Coordinators } & Junko Oda \\
\hline & & Emi Fukase \\
\hline & & Ikuko Taniguchi \\
\hline & \multirow{6}{*}{ Investigators } & Tetsuya Oda \\
\hline & & Hironobu Endo \\
\hline & & Masahiro Shimomura \\
\hline & & Kimitaka Katanazaka \\
\hline & & Shusuke Koto \\
\hline & & Takahiro Nakano \\
\hline \multirow{7}{*}{ Klinik I fur Innere Medizin - Uniklinik Koln, Germany } & Primary Investigator & Christof Scheid \\
\hline & \multirow{4}{*}{ Study Coordinators } & Andreas Zueiter \\
\hline & & Lars Pester \\
\hline & & Doreen Walter \\
\hline & & Betül Özdemir \\
\hline & \multirow{2}{*}{ Investigators } & Lukas F Frenzel \\
\hline & & Udo Holtick \\
\hline \multirow{4}{*}{ Konkuk University Hospital, South Korea } & Primary Investigator & Jeeyoung Oh \\
\hline & \multirow{3}{*}{ Investigators } & Hee Jin Kim \\
\hline & & Hyun Jin Shin \\
\hline & & Kyomin Choi \\
\hline \multirow{6}{*}{ Kumamoto University Hospital, Japan } & Primary Investigator & Taro Yamashita \\
\hline & \multirow{5}{*}{ Investigators } & Mitsuharu Ueda \\
\hline & & Teruaki Masuda \\
\hline & & Yohei Misumi \\
\hline & & Akihiko Ueda \\
\hline & & Keiichi Nakahara \\
\hline \multirow{3}{*}{ Kurume University Hospital, Japan } & Primary Investigator & Akiko Yorita \\
\hline & Study Coordinator & Seiko Tsuruhisa \\
\hline & Investigators & Takayuki Taniwaki \\
\hline
\end{tabular}




\begin{tabular}{|c|c|c|}
\hline & & Masaya Harada \\
\hline & & Taiga Moritaka \\
\hline & & Naonori Sakurada \\
\hline \multirow{3}{*}{ Mayo Clinic - Jacksonville, United States } & Primary Investigator & Elizabeth A Mauricio \\
\hline & Study Coordinator & Amber Baskin \\
\hline & Investigator & Elliot Dimberg \\
\hline \multirow{19}{*}{ Mayo Clinic - Rochester, United States } & Primary Investigator & Angela Dispenzieri \\
\hline & \multirow{18}{*}{ Investigators } & Amie Fonder \\
\hline & & Miriam Hobbs \\
\hline & & Stephen J Russell \\
\hline & & Peter Dyck \\
\hline & & Wilson Gonsalves \\
\hline & & Nelson Leung \\
\hline & & Thomas E Witzig \\
\hline & & Steven R Zeldenrust \\
\hline & & Lisa Hwa \\
\hline & & Prashant Kapoor \\
\hline & & Shaji K Kumar \\
\hline & & Yi Lin \\
\hline & & John A Lust \\
\hline & & Vincent S Rajkumar \\
\hline & & David Dingli \\
\hline & & Morie A Gertz \\
\hline & & Ronald Go \\
\hline & & Suzanne R Hayman \\
\hline \multirow{2}{*}{ Mercy Medical Research Institute, United States } & Primary Investigator & Samir Dalia \\
\hline & Investigator & Esmeralda Carrillo \\
\hline \multirow{2}{*}{ Mount Sinai Medical Center, United States } & Primary Investigator & Peter Gorevic \\
\hline & Study Coordinator & Garnette Mason \\
\hline \multirow{7}{*}{ National Taiwan University Hospital, Taiwan } & Primary Investigator & Chi-Chao Chao \\
\hline & \multirow{6}{*}{ Investigators } & Ming-Jen Lee \\
\hline & & Jen-Jen $\mathrm{Su}$ \\
\hline & & Sung-Tsang Hsieh \\
\hline & & Li-Kai Tsai \\
\hline & & Shin-Joe Yeh \\
\hline & & Chih-Chao Yang \\
\hline \multirow{4}{*}{ Northwestern University, United States } & Primary Investigator & Senda Ajroud-Driss \\
\hline & Study Coordinator & Patricia Casey \\
\hline & \multirow{2}{*}{ Investigators } & Benjamin C Joslin \\
\hline & & Patricia Casey \\
\hline \multirow{5}{*}{ Ohio State University (OSU) College of Medicine, United States } & Primary Investigator & Miriam Freimer \\
\hline & \multirow{3}{*}{ Study Coordinators } & Alison Sankey \\
\hline & & Amanda Kenepp \\
\hline & & Sarah Heintzman \\
\hline & Investigator & Samantha LoRusso \\
\hline Oita Prefectural Hospital, Japan & Primary Investigator & Youichi Hokezu \\
\hline \multirow{9}{*}{ Samsung Medical Center, South Korea } & Primary Investigator & Byoung-Joon Kim \\
\hline & \multirow{8}{*}{ Investigators } & JuHyeon Kim \\
\hline & & Ga Yeon Lee \\
\hline & & Eun Bin Cho \\
\hline & & Eun-Seok Jeon \\
\hline & & Ju-Hong Min \\
\hline & & Jin Myoung Seok \\
\hline & & Hye Lim Lee \\
\hline & & Jae Hong Park \\
\hline \multirow{4}{*}{ Shinshu University Hospital, Japan } & Primary Investigator & Yoshiki Sekijima \\
\hline & Study Coordinator & Chinatsu Miyazawa \\
\hline & \multirow{2}{*}{ Investigators } & Nagaaki Kato \\
\hline & & Dai Kishida \\
\hline
\end{tabular}




\begin{tabular}{|c|c|c|}
\hline & & Akiyo Hineno \\
\hline & & Minori Kodaira \\
\hline & & Tsuneaki Yoshinaga \\
\hline & & Teruyoshi Miyahara \\
\hline & & Akira Imai \\
\hline & & Kazuhiko Matsumoto \\
\hline \multirow{2}{*}{ Taipei Veterans General Hospital, Taiwan } & Primary Investigator & Kon-Ping Lin \\
\hline & Investigator & Yi-Chung Lee \\
\hline \multirow{9}{*}{ Umeå University Hospital, Sweden } & Primary Investigator & Jonas Wixner \\
\hline & Study Coordinator & Malin Falk \\
\hline & \multirow{7}{*}{ Investigators } & Bjorn Pilebro \\
\hline & & Ole Suhr \\
\hline & & Per Lindqvist \\
\hline & & Karin Soderberg \\
\hline & & Fatima Pedrosa-Domellöf \\
\hline & & Intissar Anan \\
\hline & & Erik Nordh \\
\hline \multirow{6}{*}{ UMHAT Aleksandrovska Sofia - Clinic of Neurology Diseases, Bulgaria } & Primary Investigator & Ivaylo Tournev \\
\hline & \multirow{5}{*}{ Investigators } & Sashka Zhelyazkova-Glaveeva \\
\hline & & Zheyna Cherneva \\
\hline & & Staiko Sarafov \\
\hline & & Teodora Chamova \\
\hline & & Sylvia Cherninkova-Gopina \\
\hline \multirow{10}{*}{ Universitaetsklinikum Muenster, Germany } & Primary Investigator & Hartmut H Schmidt \\
\hline & \multirow{2}{*}{ Study Coordinators } & Frauke Friebel \\
\hline & & Andree Zibert \\
\hline & \multirow{7}{*}{ Investigators } & Natasa Mihailovic \\
\hline & & Friederike Schubert \\
\hline & & Elena Vorona \\
\hline & & Larissa Lahme \\
\hline & & Anna Huesing-Kabar \\
\hline & & Matthias Schilling \\
\hline & & Iyad Kabar \\
\hline \multirow{7}{*}{ University College London (UCL) - Medical School, United Kingdom } & Primary Investigator & Julian D Gillmore \\
\hline & \multirow{6}{*}{ Investigators } & Ana Martinez-Naharro \\
\hline & & Liza Chacko \\
\hline & & Oliver Cohen \\
\hline & & Steven Law \\
\hline & & Tamer Rezk \\
\hline & & Helen J Lachmann \\
\hline \multirow{3}{*}{ University of Colorado, United States } & Primary Investigator & Dianna Quan \\
\hline & Study Coordinator & Brianna Blume \\
\hline & Investigator & Stacy Dixon \\
\hline \multirow{4}{*}{$\begin{array}{l}\text { University of Malaya Medical Centre-Department of Medicine, Division } \\
\text { of Neurology, Malaysia }\end{array}$} & Primary Investigator & Soon Chai Low \\
\hline & \multirow{2}{*}{ Study Coordinators } & Soo Looi Chan \\
\hline & & He Eng Lim \\
\hline & Investigator & Khean Jin Goh \\
\hline \multirow{3}{*}{$\begin{array}{l}\text { Vancouver Coastal Health Research Institute, University of British } \\
\text { Columbia, Canada }\end{array}$} & Primary Investigator & Michelle M Mezei \\
\hline & Study Coordinator & Deborah Kraus \\
\hline & Investigator & Kristin Jack \\
\hline \multirow{4}{*}{ Washington University School of Medicine, United States } & Primary Investigator & Glenn Lopate \\
\hline & \multirow{2}{*}{ Study Coordinators } & Brittany Zwijack \\
\hline & & Julaine Florence \\
\hline & Investigators & R. Brian Sommerville \\
\hline \multirow{5}{*}{ Westmead Hospital, Australia } & Primary Investigator & Graeme Stewart \\
\hline & \multirow{2}{*}{ Study Coordinators } & Julie Ryder \\
\hline & & Linda Mekhael \\
\hline & & Mark Taylor \\
\hline & Investigators & Daniel Suan \\
\hline
\end{tabular}




\begin{tabular}{|c|c|c|}
\hline & \multirow{9}{*}{$\begin{array}{l}\text { Coordinators and } \\
\text { collaborators' }\end{array}$} & Karen Wells \\
\hline & & Paula Stone \\
\hline & & Karen Wells \\
\hline & & Amenze Itoya \\
\hline & & Mercy Owusu-Sekyere \\
\hline & & Desmond Thai \\
\hline & & Ilonah Chahine \\
\hline & & Salve Pedrosa \\
\hline & & Thi Hoa (Therese) Do \\
\hline
\end{tabular}


Appendix Figure 1: Serum TTR levels (mg/L) up to Global OLE 12 months*

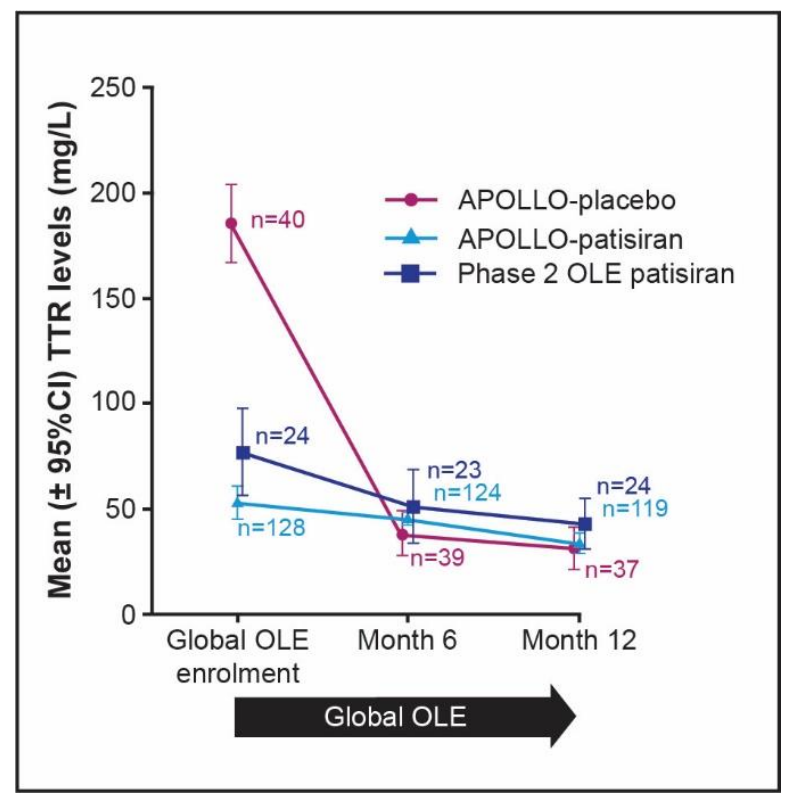

*Patients were excluded from the pharmacodynamic analysis if more than 45 days had elapsed between the last dose of patisiran in the parent study and the first dose of patisiran in the Global OLE study.

$\mathrm{CI}=$ confidence interval. OLE=open-label extension. $\mathrm{TTR}=$ transthyretin. 
Appendix Figure 2: Post hoc analysis of exposure-adjusted mortality rates by genotype and baseline NTproBNP levels in APOLLO
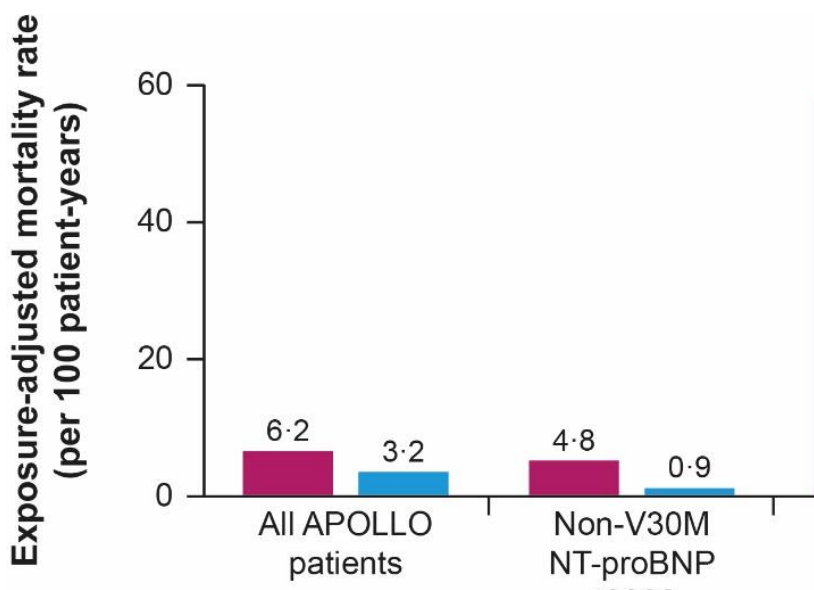
$57 \cdot 8$

NT-proBNP units (pg/mL). NT-proBNP=N-terminal prohormone of B-type natriuretic peptide. 